\title{
Sorption and Reaction of Biomass Derived HC Blends and Their Constituents on a Commercial Pt-Pd/Al $\mathrm{O}_{3}$ Oxidation Catalyst
}

\author{
Ariel Augusto Schönberger ${ }^{1,3}$ (D) - Greta Marie Haselmann ${ }^{2,3} \cdot$ Bernd Wolkenar $^{1,3} \cdot$ Simon Schönebaum ${ }^{2,3}$. \\ Peter Mauermann ${ }^{1,3} \cdot$ Stefan Sterlepper ${ }^{1,3} \cdot$ Stefan Pischinger ${ }^{1,3} \cdot$ Ulrich Simon $^{2,3}$
}

Received: 28 March 2021 / Accepted: 10 August 2021 / Published online: 25 August 2021

(c) The Author(s) 2021

\begin{abstract}
Within the Research Cluster of Excellence "The Fuel Science Center" at RWTH Aachen University, the production and application of new fuels from bio-based carbon feedstocks and $\mathrm{CO}_{2}$ with hydrogen from renewable electricity generation is being investigated. In this study, the storage and oxidation of ethanol, 1-butanol, 2-butanone, cyclopentanone, and cyclopentane as well as two blends thereof on a series production $\mathrm{Pt}-\mathrm{Pd} / \mathrm{Al}_{2} \mathrm{O}_{3}$ oxidation catalyst were investigated. Hydrocarbon (HC) storage and temperature-programmed surface reaction (TPSR) experiments were carried out to analyze their adsorption and desorption behavior. In addition, the individual HCs and both blends were investigated using Diffuse Reflectance Infrared Fourier Transform Spectroscopy (TP-DRIFTS). In general, all oxygenated HCs are adsorbed more strongly than cyclopentane due to their higher polarity. Interestingly, it could be observed that the two different blends [blend 1: ethanol (50 mol \%), 2-butanone (21 mol \%), cyclopentanone (14 mol \%) and cyclopentane (15 mol \%); blend 2: 1-butanol (45 mol \%), ethanol (29 mol \%) and cyclopentane (27 mol \%)] exhibit a different storage behavior compared to the single hydrocarbons. It was shown that the presence of 1-butanol and cyclopentane in blend 2 strongly inhibits the oxidation of ethanol. As a result, the ethanol light-off temperature was increased by at least $100 \mathrm{~K}$. A difference was also found in the storage behavior of cyclopentane. While no significant storage could be detected in the pure compound experiment, the experiments with both mixtures showed a larger amount stored. The presence of adsorbed species of the hydrocarbons and their corresponding reaction products has been demonstrated and gives an insight into the storage mechanism of blends.
\end{abstract}

Ariel Augusto Schönberger

schoenberger@vka.rwth-aachen.de

1 Institute for Combustion Engines, RWTH Aachen University, Aachen, Nordrhein-Westfalen, Germany

2 Institute of Inorganic Chemistry, RWTH Aachen University, Aachen, Nordrhein-Westfalen, Germany

3 Center for Automotive Catalytic Systems Aachen, RWTH Aachen University, Aachen, Nordrhein-Westfalen, Germany 


\section{Graphic Abstract}

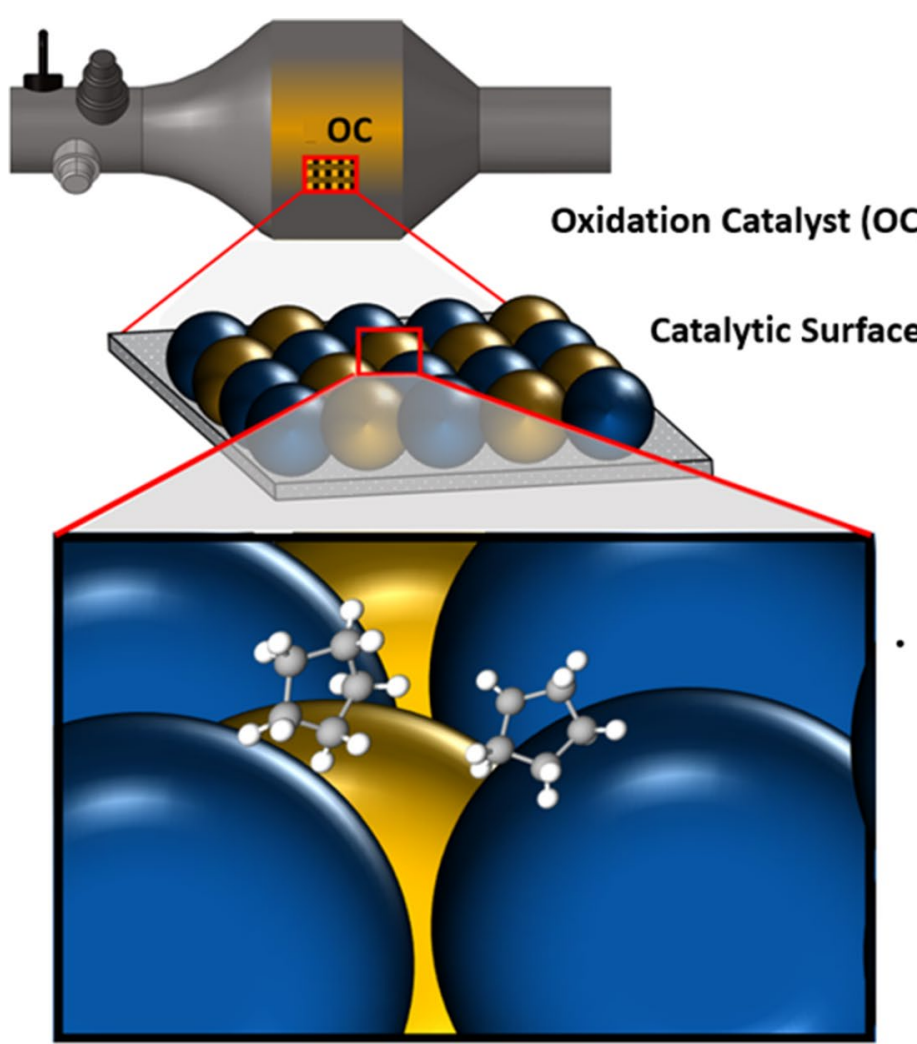

\section{Cyclopentane only}

- Only a small amount of cyclopentane can be adsorbed on the catalytic surface.

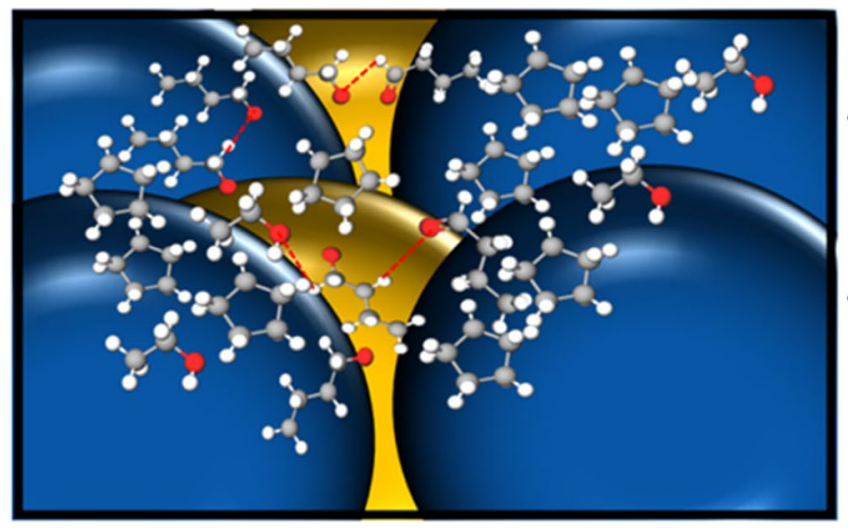

\section{Blend}

Interactions between single hydrocarbons and their reaction products.

Accumulation of cyclopentane on the nonpolar part of the other components in the blend.

Keywords Oxygenated hydrocarbons $\cdot$ Bio-hybrid Fuels $\cdot \mathrm{Pt}-\mathrm{Pd} / \mathrm{Al}_{2} \mathrm{O}_{3} \cdot$ Adsorption $\cdot$ Oxidation $\cdot$ DRIFTS

\section{Abbreviations}

$\mathrm{OC}$

$\mathrm{HC}$

TPSR

TP-DRIFTS

LGB

GHSV

OEM

\section{Oxidation catalyst}

Hydrocarbon

Temperature-programmed surface reaction

Temperature-programmed diffuse reflectance infrared Fourier transform spectroscopy

Laboratory gas test bench

Gas hourly space velocity

Original equipment manufacturer
LO Light-Off

FID Flame ionization detector

FTIR Fourier-transform infrared spectroscopy

ICP-OES Inductively coupled plasma atomic emission spectroscopy

BET Brunauer-Emmett-Teller

GHG Greenhouse gas 


\section{Introduction}

In order to limiting the increase in the global average temperature to well below $2{ }^{\circ} \mathrm{C}$ above the pre- industrial levels, special efforts are needed to reduce greenhouse gas (GHG) emissions [1]. The Research Cluster of Excellence "The Fuel Science Center" at RWTH Aachen University investigates the production and application of new bio-hybrid fuels from bio-based carbon feedstocks, $\mathrm{CO}_{2}$, and hydrogen from renewable electricity generation. The cluster research involves the production pathways from biomass, $\mathrm{CO}_{2}$, and $\mathrm{H}_{2}$ to fuels as well as the usage of these fuels in internal combustion engines and the corresponding exhaust gas aftertreatment [2-4]. A variety of different promising fuels for compression and spark ignition engines were identified and investigated for their suitability [5-12].

Lean combustion, i.e. combustion with excess air (relative air-to-fuel ratio $\lambda>1$ ), was shown to significantly increase the efficiency of spark ignition engines and thus offers the potential to reduce fuel consumption [13]. Ottenwälder et al. compared a fuel blend of $50 \mathrm{~mol} \%$ ethanol, $21 \mathrm{~mol} \%$ 2-butanone, $15 \mathrm{~mol} \%$ cyclopentane and $14 \mathrm{~mol} \%$ cyclopentanone with the currently best available fossil fuel RON 102 [14]. They showed that the conventional fuel resulted in more unstable combustion with enleanment and exceeding the 5\% IMEP standard deviation limit at $\lambda=1.6$, while the blend provided stable combustion even at $\lambda=1.7$ [5]. It was also shown that the $\mathrm{HC}$ and $\mathrm{CO}$ emissions increase with higher air-to-fuel ratios, while the $\mathrm{NO}_{\mathrm{x}}$ emissions reach their maximum value at $\lambda=1.2$ respectively 1.1 for RON 102 and then steadily decrease as $\lambda$ increases [14].

For lean-burn-engines the oxidation catalyst (OC) performs an important task during the cold start period when the exhaust gas temperature is below the light-off temperature of the catalyst: The OC operates as a hydrocarbon trap which is able to store hydrocarbons [15-21]. This HC storage is crucial as nearly $60-70 \%$ of all $\mathrm{HC}$ emissions are emitted during the cold start phase [22]. When the lightoff temperature is reached, the stored hydrocarbons can be released and be oxidized on the catalytic surface of the OC. On the other hand, it must be taken into account that stored hydrocarbons may lead to local "hotspots" during oxidation, which in turn may lead to sintering of active sites and thus to accelerated aging of the catalyst [23]. This study allows an insight into the storage and oxidation behavior of different HCs and their blends. The knowledge obtained can be used to optimize the storage behavior of OCs for the future use of alternative fuels and thus improve the cold start performance.

\section{Experimental Section}

\subsection{Catalyst Properties}

The investigated catalyst is a series production oxidation catalyst (OC) from a passenger car with a $1995 \mathrm{~cm}^{3}$ Diesel engine. It was purchased from the original equipment manufacturer (OEM) retailer. A detailed examination of the catalyst properties including ICP-OES and BET measurements were carried out by Wolkenar et al. [24].

\subsection{Laboratory Gas Test Bench Setup}

The measurement of the catalyst performance was carried out on a laboratory gas test bench (LGB). All piping on this test rig is made of grade 2 titanium. The $\mathrm{N}_{2}$ balanced gas flow was mixed from compressed gas cylinders and evaporated hydrocarbons using different mass flow controllers keeping a constant gas hourly space velocity (GHSV) of $60,000 \mathrm{~h}^{-1}$, which is often used for exhaust gas aftertreatment of internal combustion engines and is close to reality [24-26]. A detailed description of the experimental setup was given by Wolkenar et al. in [24].

\subsection{HC Storage}

For the determination of the hydrocarbon storage capacity, additional tests were conducted. For this purpose, the catalyst sample was conditioned and cooled down to a temperature of $383 \mathrm{~K}$ as in the previous measurements. After reaching this temperature, the $\mathrm{HC}$ dosage was started. The corresponding substances were dosed together with $\mathrm{O}_{2}, \mathrm{H}_{2} \mathrm{O}$ and $\mathrm{N}_{2}$ as carrier medium for a period of $30 \mathrm{~min}$. Then, the sample was purged with $\mathrm{N}_{2}$ and $\mathrm{H}_{2} \mathrm{O}$ for $10 \mathrm{~min}$ at $383 \mathrm{~K}$. In order to make the measurements realistic and at the same time take advantage of the higher accuracy provided by the more precise $\mathrm{CO}_{2}$ measuring equipment, after the purging a release phase with $10 \% \mathrm{O}_{2}$ and $\mathrm{H}_{2} \mathrm{O}$ during a temperature ramp with a gradient of $5 \mathrm{~K} / \mathrm{min}$ to a final temperature of $773 \mathrm{~K}$ was performed to remove potentially adsorbed $\mathrm{HC}$ from the catalyst surface.

At $773 \mathrm{~K}$, the sample was subsequently conditioned with $\mathrm{O}_{2}$ for a period of $10 \mathrm{~min}$ to ensure that no $\mathrm{HC}$ residues were stored on the sample. The sample was thereafter cooled to $383 \mathrm{~K}$ and the procedure was repeated. The HC concentration in the individual test corresponds to the concentration of the corresponding $\mathrm{HC}$ in a $200 \mathrm{ppm}$ blend to achieve good comparability of the tests with the pure substance and to the investigations of the blend. The selected concentrations for the investigations of the hydrocarbon storage capacity are listed in Table 1. To stabilize the dosage of small amounts, ethanol and cyclopentanone were dissolved in a precisely 
Table 1 Dosing of the different investigated hydrocarbons

\begin{tabular}{llllll}
\hline Hydrocarbon & Sum formula & Conc. TPSR & Conc. HC-storage & Boiling point & Molar mass \\
\hline 1-Butanol & $\mathrm{C}_{4} \mathrm{H}_{10} \mathrm{O}$ & $80 \mathrm{ppm}$ & $90 \mathrm{ppm}$ & $118^{\circ} \mathrm{C} \mathrm{[27]}$ & $74.12 \mathrm{~g} / \mathrm{mol}$ \\
2-Butanone & $\mathrm{C}_{4} \mathrm{H}_{8} \mathrm{O}$ & $90 \mathrm{ppm}$ & $42 \mathrm{ppm}$ & $79.6^{\circ} \mathrm{C}[28]$ & $72.11 \mathrm{~g} / \mathrm{mol}$ \\
Cyclopentane & $\mathrm{C}_{5} \mathrm{H}_{10}$ & $72 \mathrm{ppm}$ & $53 / 30 \mathrm{ppm}$ & $49{ }^{\circ} \mathrm{C}[29]$ & $70.13 \mathrm{~g} / \mathrm{mol}$ \\
Cyclopentanone & $\mathrm{C}_{5} \mathrm{H}_{8} \mathrm{O}$ & $69 \mathrm{ppm}$ & $28 \mathrm{ppm}$ & $131{ }^{\circ} \mathrm{C} \mathrm{[30]}$ & $84.12 \mathrm{~g} / \mathrm{mol}$ \\
Ethanol & $\mathrm{C}_{2} \mathrm{H}_{6} \mathrm{O}$ & $160 \mathrm{ppm}$ & $100 / 57 \mathrm{ppm}$ & $78{ }^{\circ} \mathrm{C} \mathrm{[31]}$ & $46.07 \mathrm{~g} / \mathrm{mol}$ \\
Blend 1 & - & $110 \mathrm{ppm}$ & $200 \mathrm{ppm}$ & - & - \\
Blend 2 & - & $90 \mathrm{ppm}$ & $200 \mathrm{ppm}$ & - & - \\
\hline
\end{tabular}

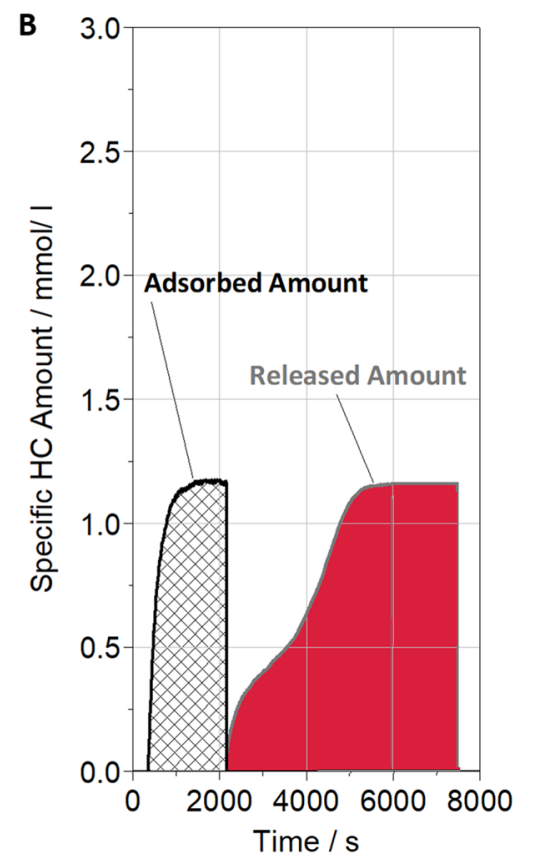

Fig. 1 Schematic illustration of the determination of $\mathrm{HC}$ storage. A The adsorbed amount (hatched area) is calculated by subtracting the area of the sum of all outgoing substances from the area of the dosed concentration. The released amount is calculated by the addition of released species (red area). B The quantities calculated from the integrals of the adsorbed and released quantities are then averaged and referred as the stored $\mathrm{HC}$ amount

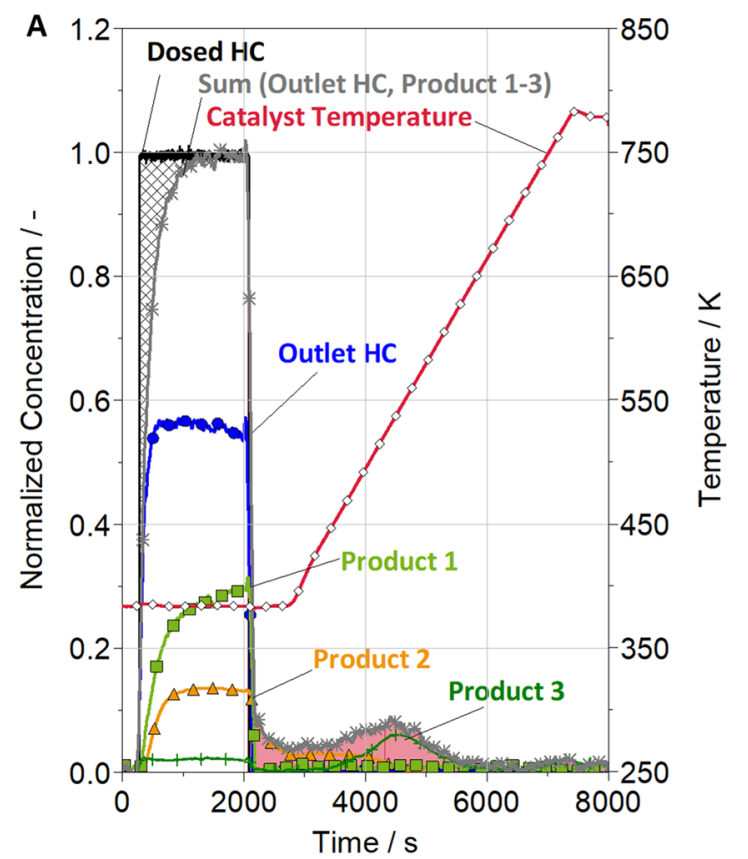

defined amount of water and dosed as a solution. The separately dosed amount of water was adjusted accordingly. The amount of adsorbed $\mathrm{HC}$ at each point in time is the difference between the amount of dosed $\mathrm{HC}$ and the amount of measured $\mathrm{HC}$. The measured $\mathrm{HC}$ quantity corresponds to the sum of the measured $\mathrm{HC}$ amount per product formed (Fig. 1 products 1-3) and the unreacted HC (outlet HC). Using ethanol as an example, at each point in time it is measured what proportion of the dosed ethanol effluents and what proportion of the ethanol is converted into the three products acetaldehyde, acetic acid, and $\mathrm{CO}_{2}$, and the sum of these is subtracted from the dosed amount to calculate the amount of $\mathrm{HC}$ stored into the catalyst. The total quantity adsorbed is finally the sum of the quantities stored at each point in time. Mathematically, this corresponds to the integral over the dosing period of the difference between the dosed quantity and the measured quantities (hatched area in Fig. 1). After the dosing phase, the catalyst is heated continuously with $5 \mathrm{~K} / \mathrm{min}$ to $773 \mathrm{~K}$. During this time, $\mathrm{HC}$ that was previously stored is released. The amount of $\mathrm{HC}$ released is the sum of the measured $\mathrm{HC}$ amounts of the individual products formed and the unreacted $\mathrm{HC}$ (outlet HC). In order to determine the total amount stored, the sum (or integral) can be formed over the time from the end of the dosing to the end of the heating of the catalyst (red area in Fig. 1A). The curves in Fig. 1B indicate the total quantity already stored or released up to the corresponding point in time, i.e. the value of the integral up to this point in time. It is assumed that the quantity released and the quantity stored are identical, which is also illustrated by Fig. 1B. In order to account for potential measurement inaccuracies, the average of the measured adsorbed and released quantities is taken to determine the actual stored HC quantity. In order to increase the accuracy of the results, a large number of storage and release phases were carried out, resulting in the error indicators shown in Figs. 2 and 3.

\subsection{TPSR Measurements}

To examine the oxidative behavior of the different hydrocarbons (1-butanol, 2-butanone, cyclopentane, cyclopentanone, ethanol, and two blends) on the catalyst, temperature-programmed surface reaction (TPSR) experiments have been 
Fig. 2 Specific quantity of stored hydrocarbons, deterquantity of the corresponding $\mathrm{HC}$ in $\mathrm{mmol} / \mathrm{l}$, stored $\mathrm{HC}$ in pure experiments (grey), stored $\mathrm{HC}$ in blend 1 (green), storage phase at $\mathrm{T}=383 \mathrm{~K}$ and GHSV $=60000 \mathrm{~h}^{-1}$, Gas composition: $8 \% \mathrm{H}_{2} \mathrm{O}, 8 \% \mathrm{O}_{2}$, ance: $\mathrm{N}_{2}$ mined from stored and released $0 \% \mathrm{CO}_{2}$, $\mathrm{HC}$ : see Table 1, bal-

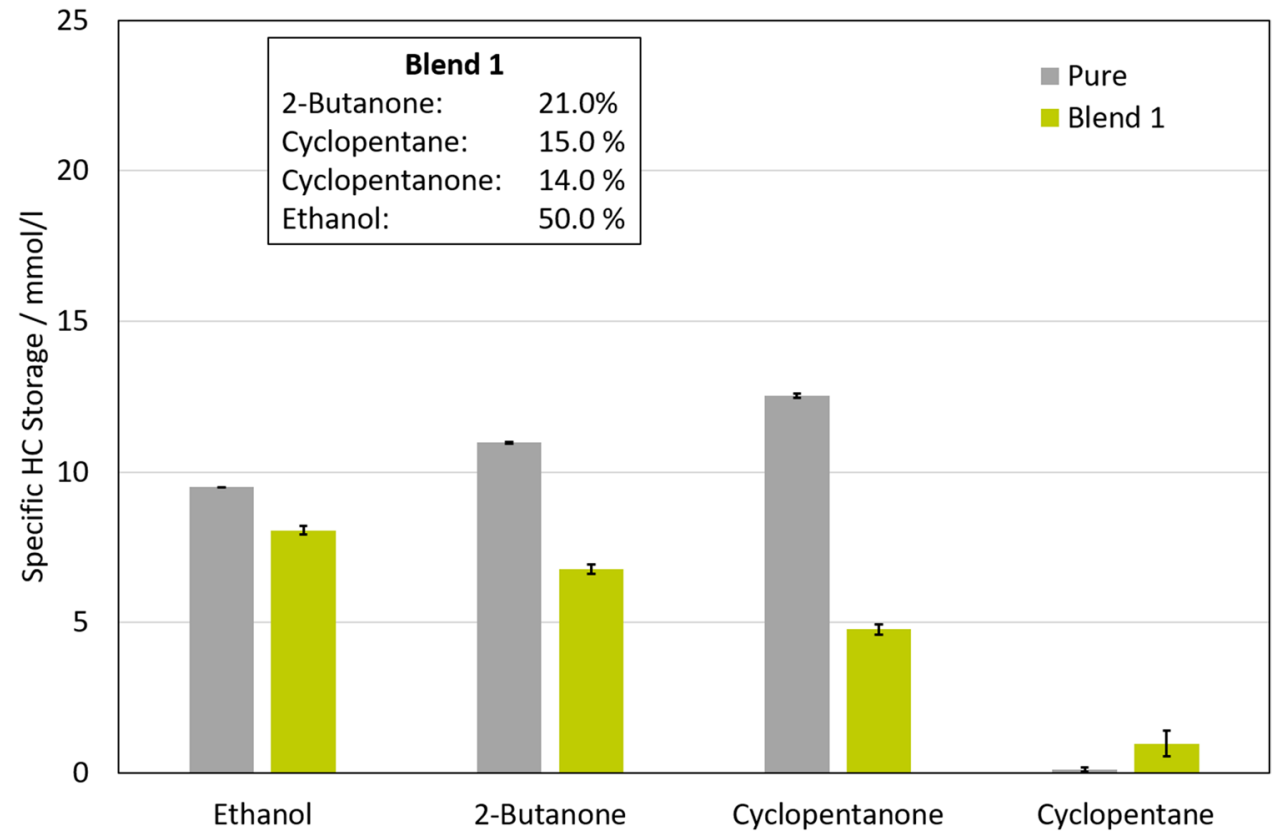

Fig. 3 Specific quantity of stored hydrocarbons, determined from stored and released quantity of the corresponding $\mathrm{HC}$ in $\mathrm{mmol} / \mathrm{l}$, stored $\mathrm{HC}$ in pure experiments (grey), stored $\mathrm{HC}$ in blend 2(orange), storage phase at $\mathrm{T}=383 \mathrm{~K}$ and $\mathrm{GHSV}=60,000 \mathrm{~h}^{-1}$, Gas composition: $8 \% \mathrm{H}_{2} \mathrm{O}, 8 \% \mathrm{O}_{2}$, $0 \% \mathrm{CO}_{2}$, HC: see Table 1, balance: $\mathrm{N}_{2}$

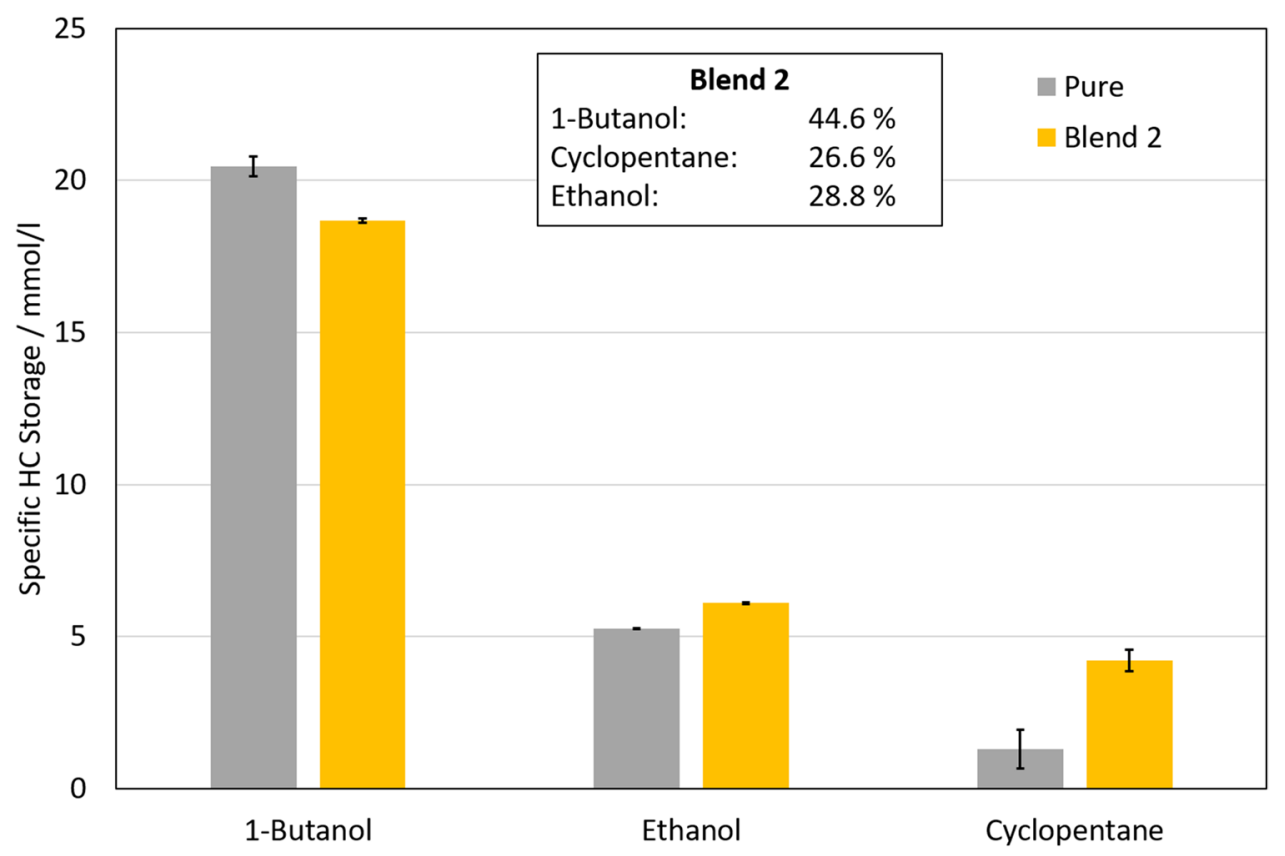

carried out. For all measurements, the feed gas contained $8 \%$ $\mathrm{O}_{2}, 8 \% \mathrm{H}_{2} \mathrm{O}$, and varying concentrations of the respective $\mathrm{HC}$ (see Table 1), with $\mathrm{N}_{2}$ as balance. The used HC concentration was set to obtain a gas mixture corresponding to a relative air-fuel-ratio of 2.96 if there were additionally $8 \%$ of $\mathrm{CO}_{2}$. This enables a comparable amount of $\mathrm{C}$ and $\mathrm{H}$ to react on the catalyst in all experiments. For each experiment, the test procedure started with a catalyst pre-conditioning at $773 \mathrm{~K}$ with $8 \% \mathrm{O}_{2}$ and $8 \% \mathrm{H}_{2} \mathrm{O}$ to remove potentially adsorbed $\mathrm{HC}$ and to oxidize the catalyst surface. Afterwards, the catalyst was cooled down to $383 \mathrm{~K}$ and filled with the respective HC. Once the FID signal has reached a constant value, the temperature was increased with a heating rate of $5 \mathrm{~K} / \mathrm{min}$ to $773 \mathrm{~K}$.

For concentration analysis by FTIR, various evaluation methods from the instrument manufacturer were modified for the investigation of exhaust gas components. In addition, FID and mass spectrometer data were used for verification. 


\subsection{TP-DRIFTS}

Ceramic chips, that can be resistively heated through integrated electrodes, were coated with the catalyst material. The chips were then loaded with the pure HC or blend at the LGB. TP DRIFTS experiments were consecutively performed in a Vertex 70 FTIR spectrometer (Bruker Corporation, Billerica, MA, USA) equipped with a Praying Mantis mirror setup (Harrick Scientific Products, Inc., Pleasantville, NY, USA) and a custom-made DRIFTS cell. The temperature ranged between 323 and $673 \mathrm{~K}$ at a constant $\mathrm{N}_{2}$ flow of $100 \mathrm{ml} / \mathrm{min}$. Further details about the experimental conditions and sample preparation can be found in [24].

\section{Results and Discussion}

\subsection{HC-Storage}

Since the storage capacity depends on the properties of the corresponding $\mathrm{HC}$, the results show differences between the species with different functional groups. In a first step, single component measurements were conducted. For cyclopentane, no HC storage capacity could be detected in the single component experiments. For 1-butanol, the largest absolute storage amongst all $\mathrm{HC}$ of $20.5 \mathrm{mmol} / \mathrm{l}$ could be observed. The second highest storage capacity was measured with cyclopentanone (12.5 mmol/l). For 2-butanone, a HC storage of $11.0 \mathrm{mmol} / \mathrm{l}$ was measured (Fig. 2). The measurements with ethanol resulted in an $\mathrm{HC}$ storage of $5.3 \mathrm{mmol} / \mathrm{l}$ for a dosage of $57 \mathrm{ppm}$ and $9.5 \mathrm{mmol} / \mathrm{l}$ for a dosage of $100 \mathrm{ppm}$.
As already found by Wolkenar et al. [24], it could be shown that oxygenated molecules are better stored than molecules without oxygen in the molecular structure. A closer look at the results of the single component measurements shows that the storage for the investigated $\mathrm{HC}$ depends on the functional group as well as on the number of $\mathrm{C}$ atoms in the molecule. This results in a storage of $3 \mathrm{mmol} / \mathrm{l} \mathrm{per}$ $\mathrm{C}$-atom for ketones and $5 \mathrm{mmol} / \mathrm{l}$ per $\mathrm{C}$-atom for alcohols. When comparing the stored quantities during the single substance measurements with the results of the mixtures, some differences are noticeable: Fig. 1 shows the storage of the blends compared to its pure constituents. In general, it can be said that all substances-with the exception of cyclopentane-were stored in blend 1 to a lower degree than in the experiments with the pure substances (Fig. 2). Large differences between the individual substance classes can be observed. While the difference between the stored ethanol in blend 1 and as pure substance is 15\%,2-butanone and cyclopentanone show a reduction of $38 \%$ and $62 \%$ respectively. In contrast to the studies with cyclopentane as a pure substance, a storage of cyclopentane can be observed with blend 1 . However, the amount stored is small. Blend 2 shows a slightly different behavior (Fig. 3): although in this case the stored amount of the main component is also significantly lower (9\%) compared to the stored amount in the test with the pure substance, the other components show a significantly improved storage behavior. Thus, the amount of stored ethanol and cyclopentane increases by $16 \%$ and $224 \%$, respectively. When looking at the cumulative selectivities during storage and release phase, it is noticeable that ethanol in blend 2 not only shows the lowest conversion, but also that no partially oxidized products can be detected (Fig. 4).
Fig. 4 Selectivities of acetaldehyde, acetic acid, and $\mathrm{CO}_{2}$ cumulated from ethanol storage and release in both blends and in the studies of the pure components at the corresponding concentration as they are also present in the respective blend. The black line shows the cumulative conversion of ethanol during the storage and release phases. Storage phase at $\mathrm{T}=383 \mathrm{~K}$ and $\mathrm{GHSV}=60,000 \mathrm{~h}^{-1}$, Gas composition: $8 \% \mathrm{H}_{2} \mathrm{O}, 8 \% \mathrm{O}_{2}$, $\mathrm{HC}$ : see Table 1, balance: $\mathrm{N}_{2}$

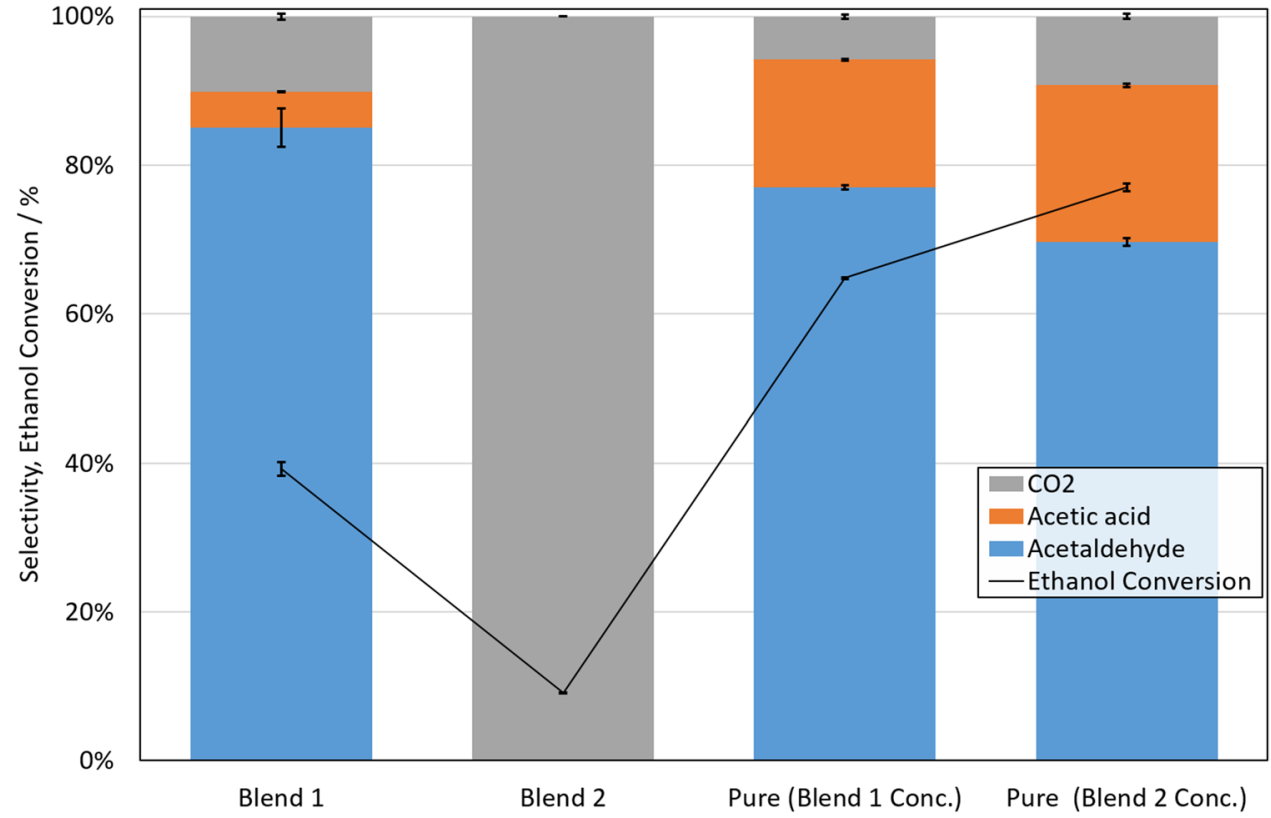


Fig. 5 Yield of acetaldehyde, acetic acid, and $\mathrm{CO}_{2}$ released from ethanol during release phase relative to the whole amount removed from storage in both blends and in the studies of the pure components at the corresponding concentration as they are also present in the respective blend

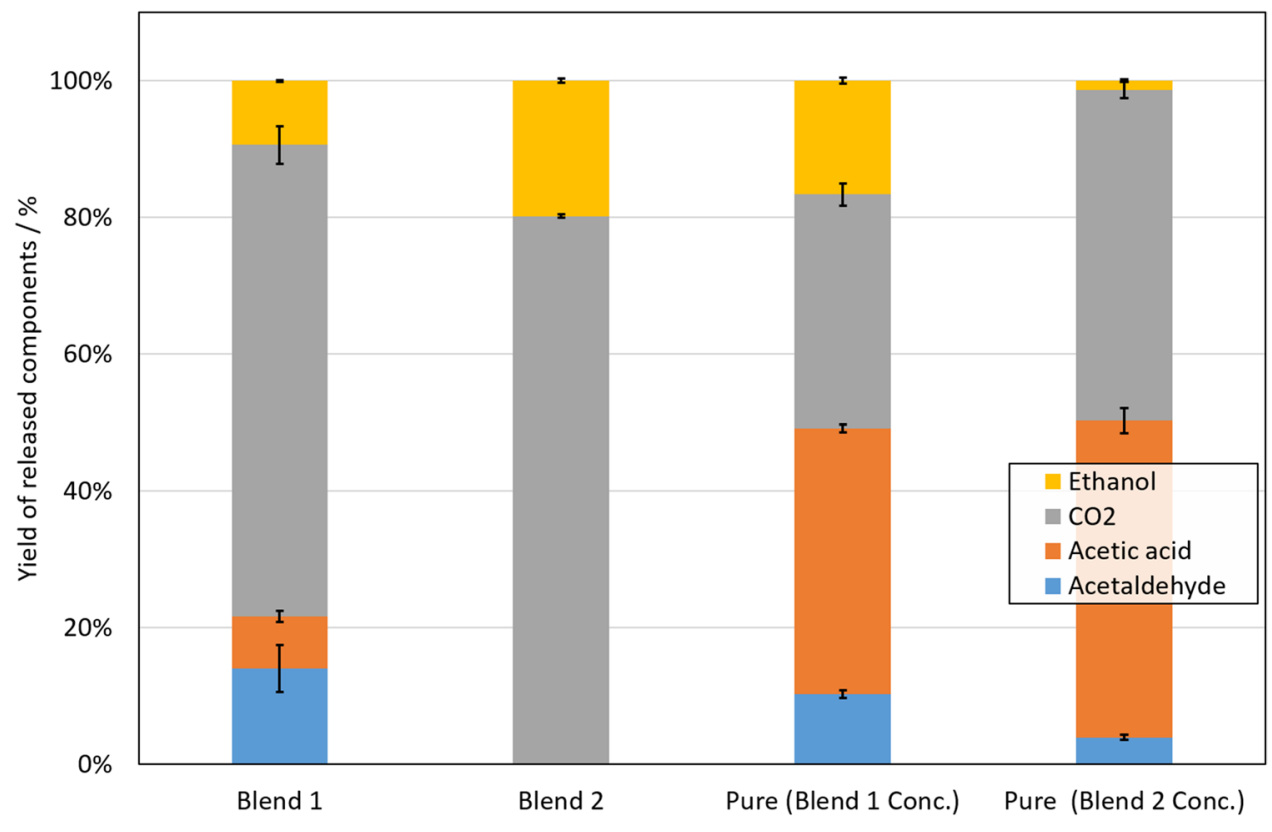

In general, the data show that ethanol is converted worse in both blends than in the measurements with ethanol as pure substance. While the ratio between acetic acid and $\mathrm{CO}_{2}$ in the released amount is about 1:1 in the measurements with pure ethanol (Fig. 5), both blends show a changed behavior: the substances released from ethanol in blend 1 contain significantly less acetic acid and a slightly increased amount of acetaldehyde. However, most of the stored ethanol is released as $\mathrm{CO}_{2}$, although it is unclear whether this amount was stored as ethanol or as an intermediate or was converted to $\mathrm{CO}_{2}$ on release. Blend 2 does not show any products from partial oxidation even during the removal phase; in particular, it shows that about $20 \%$ of the ethanol stored is desorbed unreacted.

Also when looking at the substances released from the stored 1-butanol (Fig. 6), it can be seen that the proportion of unreacted 1-butanol is slightly increased compared to the comparative measurement without further components. On the other hand, the proportion of butyric acid is increased, while the fraction of $\mathrm{CO}_{2}$ drops from 43 to $24 \%$.

Similar results are also shown for cyclopentane and cyclopentanone. Although these are not as strongly increased
Fig. 6 Yield of butyraldehyde, butyric acid, and $\mathrm{CO}_{2}$ released from 1-butanol during release phase relative to the whole amount removed from storage in blend 2 and during the study of the pure component

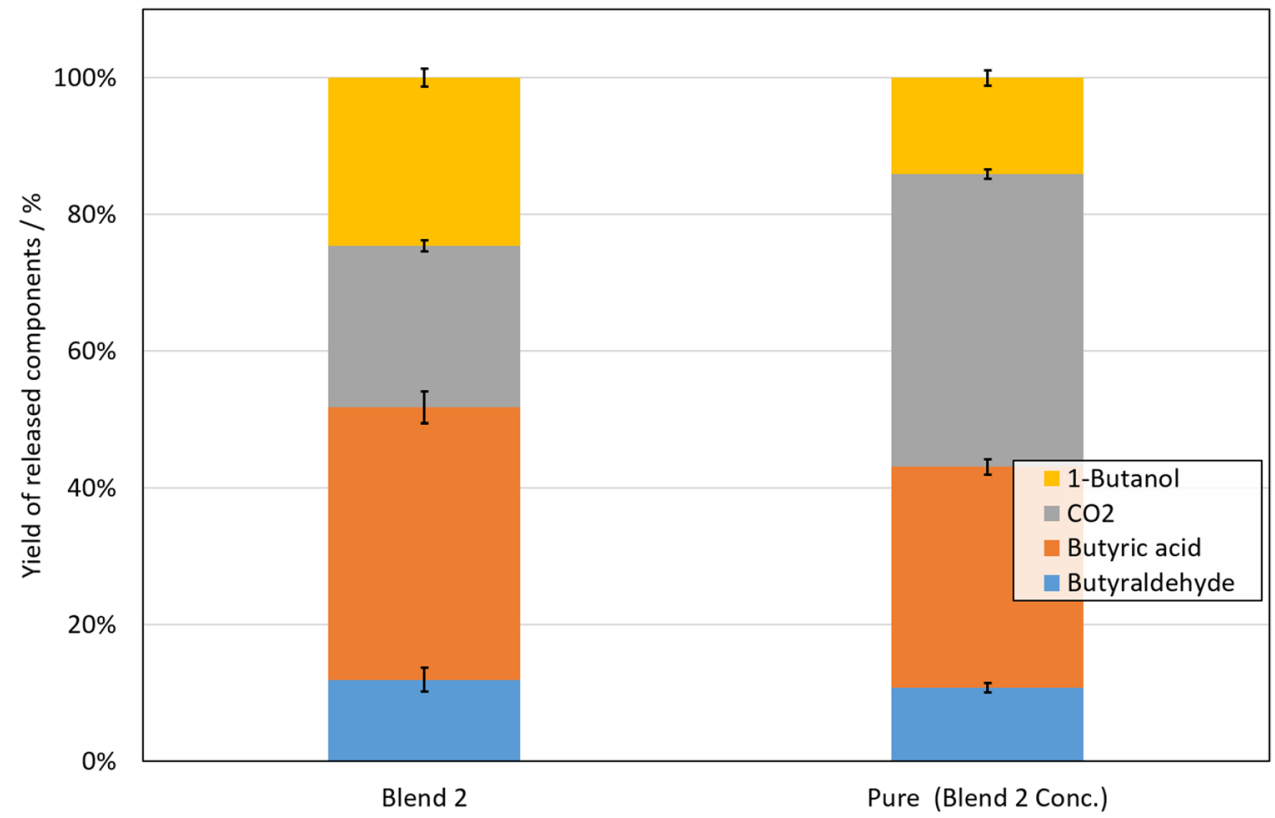


as for the two previously mentioned hydrocarbons, they are nevertheless significant, thus the amount of unreacted hydrocarbons in comparison of pure cyclopentane to blend 1 increases from $59 \pm 6$ to $71 \pm 1 \%$. In the case of cyclopentanone, the fraction of unreacted hydrocarbons in the $\mathrm{HC}$ released increases from $47 \pm 1$ to $79 \pm 1 \%$ in comparison of pure cyclopentane to blend 1 . Only 2-butanone shows a different behavior. Thus, the amount of unreacted 2-butanone in the released quantity drops from $69 \pm 3 \%$ in the comparative measurement with the pure component to a value of $56 \pm 2 \%$ without the formation of any by-products being observable. In general, the observable deterioration of the conversion in the measurements with the blends could be explained by the deactivation due to the presence of carboxyl groups as they occur in the acids. This fact would also fit with the observations from the literature [32-36]. Only the enhanced conversion of 2-butanone in blend 1 seems to be in contradiction with the other observations. This fact could be due to a reaction pathway which proceeds only by the presence of the other blend components or their intermediates.

\subsection{TPSR-Measurements}

As already observed by Wolkenar et al. [24] during the TPSR investigations, some of the investigated $\mathrm{HC}$ react to $\mathrm{CO}_{2}$ on this catalyst at the beginning of the initial storage phase at temperatures as low as $383 \mathrm{~K}$. Figure 7 shows the $\mathrm{CO}_{2}$ yield for each pure component during the storage before the TPSR starts.

It is not surprising that at the low temperature of $383 \mathrm{~K}$ cyclopentane is not converted to $\mathrm{CO}_{2}$ in significant amounts due to its relatively high stability. Both alcohols, on the other hand, show at the low temperature of $383 \mathrm{~K}$ a sudden increase in $\mathrm{CO}_{2}$ concentration at the beginning of the dosage. Subsequently, its concentration decreases steadily over time. This behavior has already been described in literature and points to an inhibition of the oxidation reactions due to carboxyl species formation e.g. formate with advancing storage of the $\mathrm{HC}$ at the active sites [24, 32, 33, 35]. Oh et al. described a mechanism which explained the formation of surface carboxyl species from $\mathrm{C}_{3} \mathrm{H}_{6}$ on a diesel oxidation catalyst with Pt [33]. I.e., the increase at the beginning is caused by oxidation of $\mathrm{HC}$ with the $\mathrm{O}_{2}$ on the catalyst surface. With decreasing $\mathrm{O}_{2}$ or with increasing $\mathrm{HC}$ loading and the resulting formation of carboxylic species on the surface, the $\mathrm{CO}_{2}$ production decreases. Also, for both ketones, 2-butanone and cyclopentanone, this behavior is shown during $\mathrm{CO}_{2}$ release at $383 \mathrm{~K}$. After a short steep increase at the beginning of the dosage and a subsequent steady decrease, an almost stable $\mathrm{CO}_{2}$ production settles out after a period of $3000 \mathrm{~s}$. At this point, the descending order of the $\mathrm{CO}_{2}$ yield is as follows: ethanol, 1-butanol, 2-butanone, cyclopentanone and cyclopentane. Thus, both alcohols lead to higher $\mathrm{CO}_{2}$ yields than with/from the two ketones, and these in turn lead to a higher $\mathrm{CO}_{2}$ production than the alkane cyclopentane. This can again be possibly explained by the fact that alkanes are more stable than ketones and the latter in turn are more stable than alcohols. Comparing both alcohols and both ketones, it can be observed that in both cases the shortchain molecules lead to a higher $\mathrm{CO}_{2}$ production than the long-chain molecules. At $383 \mathrm{~K}$, the maximum $\mathrm{CO}_{2}$ yield during the 2-butanone dosage is about $2 \%$ lower than the maximum $\mathrm{CO}_{2}$ yield at the same temperature in the experiment with cyclopentanone. A possible explanation for the
Fig. $7 \mathrm{CO}_{2}$ yield for different hydrocarbons from pure substance measurement, filtered by a Savitzky-Golay-Function of $3^{\text {rd }}$ polynomial order and a window size of $90, \mathrm{~T}=383 \mathrm{~K}$ and GHSV $=60,000 \mathrm{~h}^{-1}$, Gas composition: $8 \% \mathrm{H}_{2} \mathrm{O}, 8 \% \mathrm{O}_{2}$, $0 \% \mathrm{CO}_{2}$, HC: see legend, balance: $\mathrm{N}_{2}$

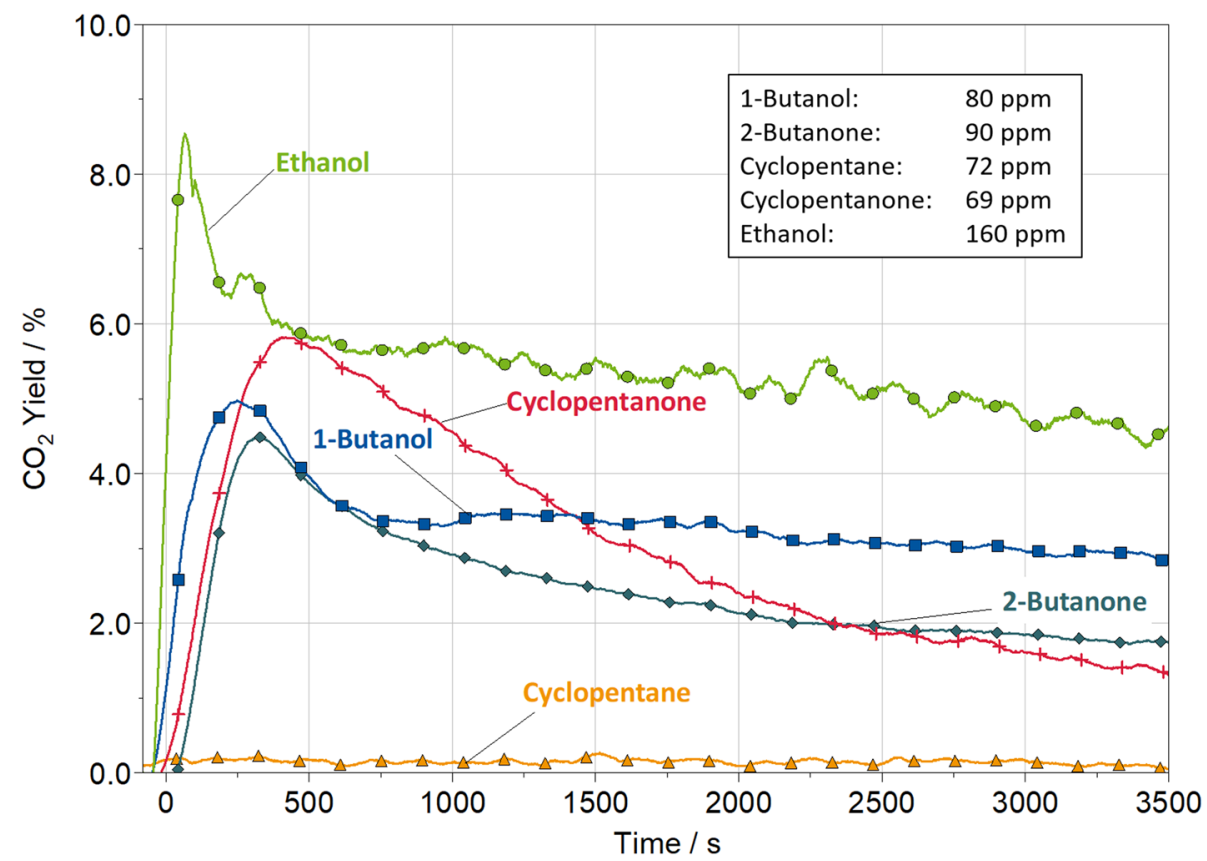




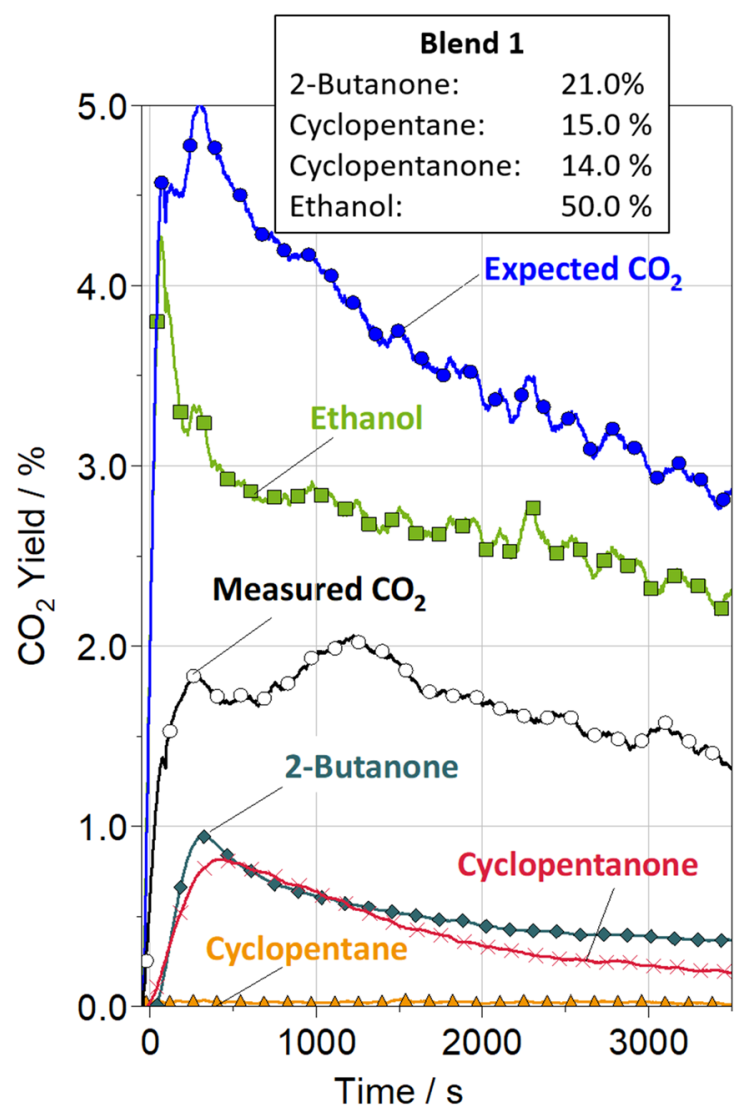

Fig. 8 Weighted $\mathrm{CO}_{2}$ yield, the blue line shows the expected $\mathrm{CO}_{2}$ yield with the same conversion of $\mathrm{HC}$ in the blend as in the pure substance tests, black is the actual amount of $\mathrm{CO}_{2}$ released from the blend. On the left side the $\mathrm{HC}$ is shown in the composition of blend 1

lower reactivity of 2-butanone compared to cyclopentanone could be steric hindrance.

Considering the results from the measurements with the blends, it is noticeable that the amount of $\mathrm{CO}_{2}$ formed during the storage of both mixtures at $383 \mathrm{~K}$ does not correspond to the amount of $\mathrm{CO}_{2}$ that would be expected from the weighted sum of the individual components based on the single experiments. While the difference between the expected and the measured amount of $\mathrm{CO}_{2}$ for blend 1 is about $2 \%$-points, there is a difference of $0.8 \%$-points for blend 2. It is remarkable that in blend 1 the amount of $\mathrm{CO}_{2}$ that would have to be produced from ethanol alone exceeds the actual measured concentration by slightly more than $1 \%$-point (Fig. 8). These facts indicate that the presence of the other components leads to a reduced conversion of some of the hydrocarbons.

Depending on the dosed hydrocarbon, some reaction products could be detected in addition to the $\mathrm{CO}_{2}$ already mentioned during the storage phase at $383 \mathrm{~K}$. The formed products were acetaldehyde, acetic acid, butyraldehyde, butyric acid and small amounts of methane as well as $\mathrm{CO}_{2}$.

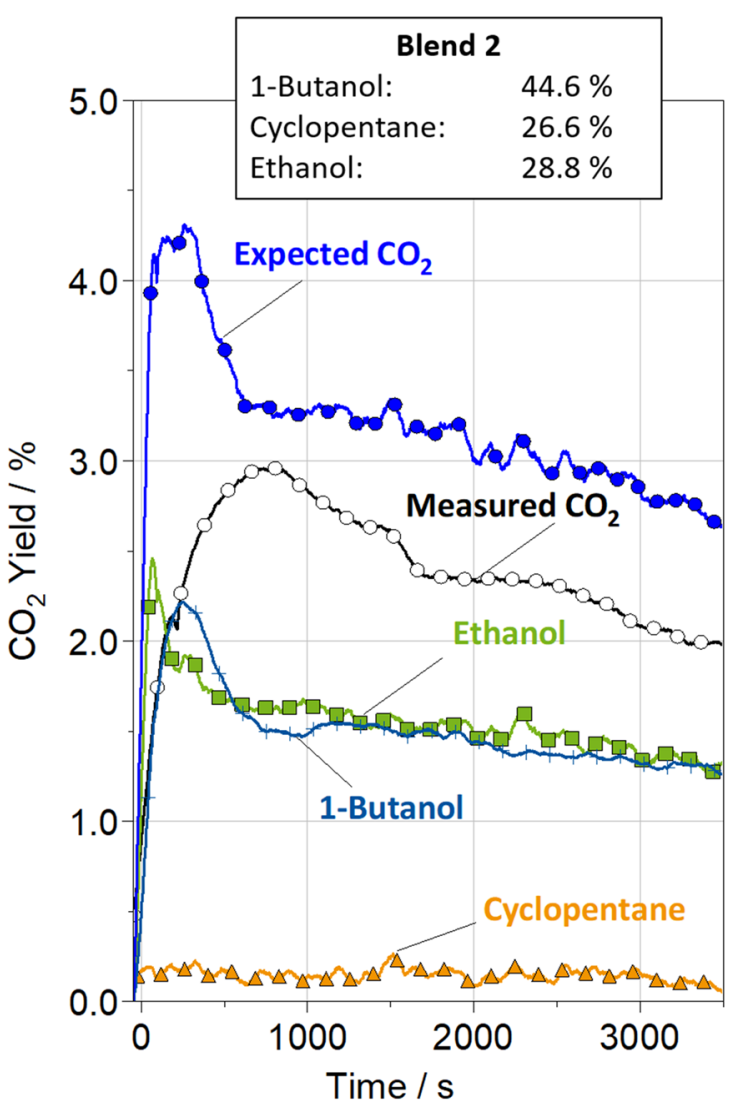

and on the right side of blend 2, filtered by a Savitzky-Golay-Function of $3 \mathrm{rd}$ polynomial order and a window size of $90, \mathrm{~T}=383 \mathrm{~K}$ and GHSV $=60,000 \mathrm{~h}^{-1}$, gas composition: $8 \% \mathrm{H}_{2} \mathrm{O}, 8 \% \mathrm{O}_{2}, 0 \% \mathrm{CO}_{2}, \mathrm{HC}$ : see legend, balance: $\mathrm{N}_{2}$

One substance which could not be reliably identified by the specially developed FTIR evaluation method, was butyric acid, which is formed during the oxidation of 1-butanol. However, the formation of butyric acid could be qualitatively detected by MS. Therefore, the amount of butyric acid formed was determined from the difference between all known detectable substances that could be detected by FTIR measurement and the FID value for the total hydrocarbons. This calculated value was then corrected according to the dosed and measured $\mathrm{C}$ balance. While for the alcohols, 1-butanol and ethanol, significant amounts $(>50 \%)$ were already converted at $383 \mathrm{~K}$ and products from partial oxidations could be detected, both ketones showed no reaction products other than $\mathrm{CO}_{2}$ at this temperature. For cyclopentane no significant conversion was observable at $383 \mathrm{~K}$.

The typical reaction sequence of alcohol decomposition on Pt, Pd and other noble metals includes the formation of an alkoxide intermediate forming aldehyde, carbonic acid and $\mathrm{CO}_{2}$ as reaction products [37-39]. Regardless of this, the acidity of the supporting $\mathrm{Al}_{2} \mathrm{O}_{3}$ can promote both the dehydrogenation and dehydration of ethanol and can thus 
also lead to the formation of acetaldehyde and acetic acid [38-40]. It is known that $\mathrm{Al}_{2} \mathrm{O}_{3}$ has a poor adsorption behavior for ethanol because of its low specific surface area [41]. It is therefore assumed that the storage assigned to ethanol is mainly caused by adsorbed reaction products.

The steep gradient in the acetaldehyde concentration at the beginning of the TPSR could be an indication that a small part of the stored ethanol on the catalytic surface formed an intermediate that can be released as acetaldehyde. Aldehydes can be bonded to the surface via two possible mechanisms, one via both carbon and oxygen atoms of its carbonyl function group $\left[\eta^{2}(\mathrm{C}, \mathrm{O})\right.$-conformation $]$ and the other way via its oxygen atom only $\left[\eta^{l}(\mathrm{O})\right.$-conformation] [37]. Oxygen-loaded surfaces support the $\eta^{l}(\mathrm{O})$-conformation of aldehyde intermediates which are more likely to desorb than to further decompose analogue to the $\eta^{2}(\mathrm{C}, \mathrm{O})$-conformation of aldehydes [37, 42].

Due to the performed pre-treatment of the sample with $8 \% \mathrm{O}_{2}$, a high oxygen loading of the surface can be assumed. On the other hand, after starting the temperature ramp at $398 \mathrm{~K}$, we observe an increasing acetaldehyde concentration after $t=4000 \mathrm{~s}$ (Fig. 9), while the observed ethanol concentration drops. We therefore attribute this behavior to a higher formation rate of acetaldehyde rather than thermal desorption. As the temperature rises, there is also an increased formation of acetic acid. The maximum acetic acid concentration is reached at $473 \mathrm{~K}$. This is in accordance with the results of Avgouropulos et al. when using unpromoted Pt/ $\mathrm{Al}_{2} \mathrm{O}_{3}$ [38]. This increase in acetic acid concentration shows that a large part of the stored ethanol reacts on the surface to acetic acid and then is released with increasing temperature. In addition to acetaldehyde and acetic acid, a small amount of methane can also be detected in the ethanol test. It is noticeable that the release of methane is only observable in the temperature range of 394-630 K with two maxima at ca. $433 \mathrm{~K}$ and $555 \mathrm{~K}$.

The methane peak and the shoulder of $\mathrm{CO}_{2}$ at $433 \mathrm{~K}$ could also be an indication for a decarbonylation of an aldehyde intermediate species on $\mathrm{Pd}^{0}$ sites generating equimolecular amounts of methane and $\mathrm{CO}$ which would be followed by the oxidation of $\mathrm{CO}$ to $\mathrm{CO}_{2}[40,43]$. These $\mathrm{Pd}^{0}$ species could be generated by ethanol oxidative dehydrogenation [40]. However, it must also be noted that the quantities of methane formed are very small. 1-butanol shows a similar behavior on the catalyst as ethanol. The formation of the corresponding aldehyde and the corresponding carboxylic acid can also be observed here. However, no compounds with a small number of carbon atoms could be observed in the reaction of 1-butanol except $\mathrm{CO}_{2}$. While the investigations with cyclopentanone and cyclopentane did not reveal any oxidation products apart from $\mathrm{CO}_{2}$, the investigation of 2-butanone yielded acetic acid and methane.

The formation of acetic acid from 2-butanone has been known in the literature for a long time [44-46]. Among others, Jahan et al. reported how the selectivity of acetic acid is increased by the presence of water $[44,46]$. The investigations with 2-butanone as pure component showed that over the entire dosage range of 383-773 K, an acetic acid and methane yield of $2.5 \%$ and $0.5 \%$ respectively was achieved. A steep increase in acetic acid concentration of $15 \%$ at $500 \mathrm{~K}$ indicates that stored 2-butanone is converted to acetic acid on the catalyst surface and this formed acetic acid is largely released when the temperature is increased. At
Fig. 9 Temperature-programmed surface reaction (TPSR) from $T=383$ to $773 \mathrm{~K}$ and $\mathrm{GHSV}=60,000 \mathrm{~h}^{-1}$, Gas composition: $8 \% \mathrm{H}_{2} \mathrm{O}, 8 \% \mathrm{O}_{2}$, $0 \% \mathrm{CO}_{2}, 160$ ppm ethanol, balance $\mathrm{N}_{2}$. All data filtered by a Savitzky-Golay-Function of 3rd polynomial order and a window size of 90. Left axis: Normalized hydrocarbon concentration, versus time since start of TPSR; right axis: mean catalyst temperature versus time

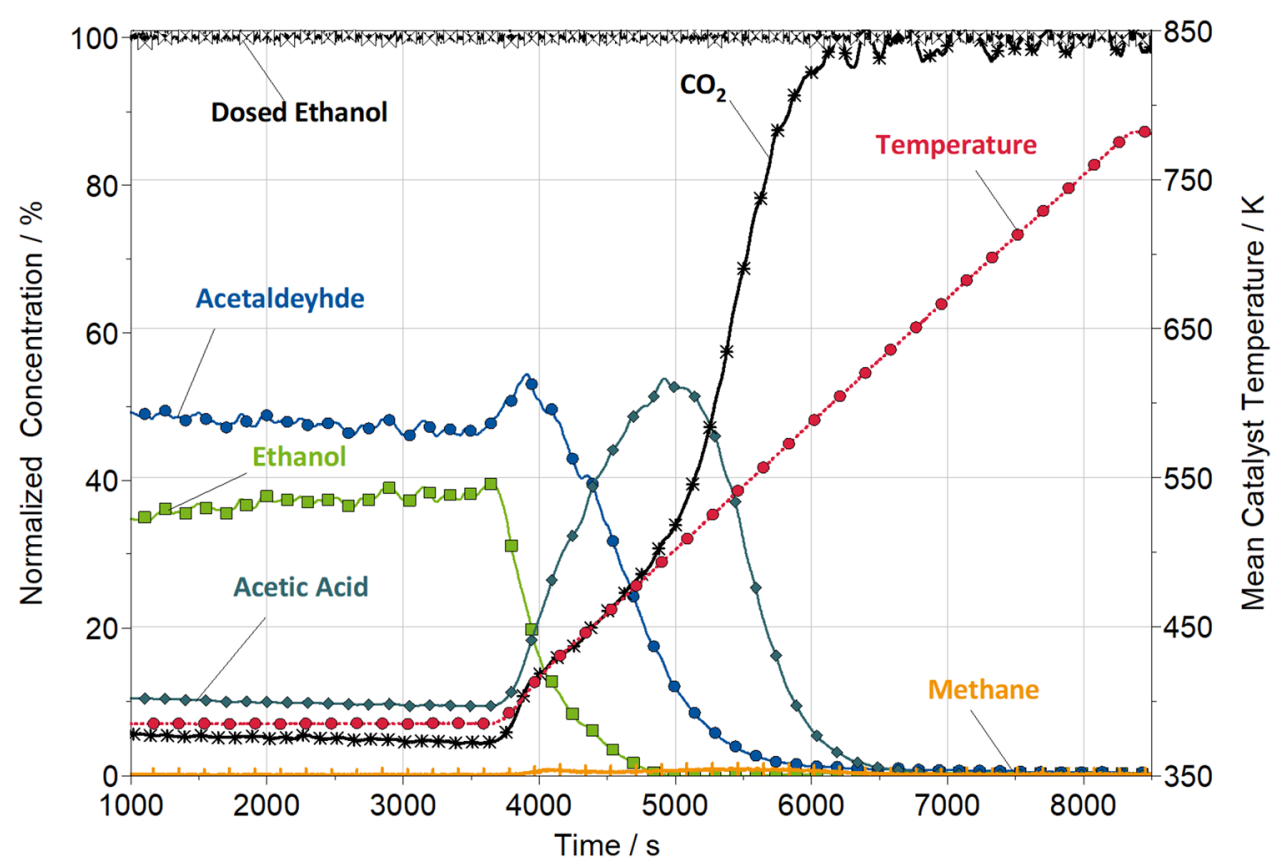


Table 2 Light-off temperatures

\begin{tabular}{llll}
\hline Hydrocarbon & LO-temp/pure & $\begin{array}{l}\text { LO-temp./ } \\
\text { blend 1 }\end{array}$ & $\begin{array}{l}\text { LO-temp./ } \\
\text { blend 2 }\end{array}$ \\
\hline 1-Butanol & $<383 \mathrm{~K}$ & - & $422 \mathrm{~K}$ \\
2-Butanone & $473 \mathrm{~K}$ & $495 \mathrm{~K}$ & - \\
Cyclopentane & $576 \mathrm{~K}$ & $601 \mathrm{~K}$ & $558 \mathrm{~K}$ \\
Cyclopentanone & $505 \mathrm{~K}$ & $542 \mathrm{~K}$ & - \\
Ethanol & $<383 \mathrm{~K}$ & $430 \mathrm{~K}$ & $483 \mathrm{~K}$ \\
Weighted sum & - & $485 \mathrm{~K}$ & $476 \mathrm{~K}$ \\
\hline
\end{tabular}

temperatures above $645 \mathrm{~K}$, no more acetic acid production could be detected.

When comparing the single hydrocarbons and the blends, large differences in the conversion on the catalyst are revealed. The light-off temperature (LO-temperature) is the temperature at which the conversion of a substance reaches $50 \%$. All measured LO-temperatures and the sum product for both blends are listed in Table 2. The example of ethanol shows that in the presence of the other blend components, the LO-temperature of ethanol is increased. While in blend 1 the LO-temperature for ethanol is increased by $47 \mathrm{~K}$ to a value of $430 \mathrm{~K}$, the presence of 1-butanol and cyclopentane in blend 2 causes an increase by $100 \mathrm{~K}$ to $483 \mathrm{~K}$ (Fig. 10). In the literature, LO-temperatures of $423-523 \mathrm{~K}$ for the conversion of ethanol have been observed for $\mathrm{Pd} / \mathrm{Al}_{2} \mathrm{O}_{3}$ catalysts by Liu et al. [41]. The decrease in ethanol conversion is already apparent at $383 \mathrm{~K}$. The analysis of blend 1 shows that the conversion of ethanol to acetaldehyde and acetic acid is significantly lower (average conversion of $45 \%$ ) than the measurement with pure ethanol (average conversion of
$64 \%)$. This discrepancy increases further at the dosage of blend 2 , so that at a temperature of $383 \mathrm{~K}$ only an average ethanol conversion of $17 \%$ can be observed.

In general, it can be stated that the other hydrocarbons in the presence of the other blend constituents also show a significantly reduced turnover. The only exception is cyclopentane in blend 2 with an increased turnover leading to a small decrease of the LO-temperature of $18 \mathrm{~K}$ (Fig. 11).

\subsection{TP-DRIFTS}

Figure $12 \mathrm{a}$ and $\mathrm{b}$ show the TP-DRIFTS difference spectra of blend 1 and 2, respectively, in the temperature range between 323 and $673 \mathrm{~K}$.

Since no oxygen is fed, no further oxidation reaction is expected to occur during TP-DRIFTS experiments. Observed bands are thus attributed to surface species that have formed during the LGB experiments, including reaction intermediates and products. Several characteristic features in agreement with our previous experiments can be observed [24]. The absorption band at $3700 \mathrm{~cm}^{-1}$ becomes stronger with increasing temperature. This corresponds to the $\nu(\mathrm{OH})$ of surface hydroxyl groups of the alumina support which are generated after the desorption of the HC [47]. Blend 2 exhibits additionally a broad band between ca. 3500 and $3100 \mathrm{~cm}^{-1}$ which has previously been ascribed to $-\mathrm{OH}$ interactions through intermolecular $\mathrm{H}$ bonding. The decrease of this band with increasing temperature is attributed to the desorption of previously condensed phases on the catalyst surface [24]. Characteristic absorption bands of the $\nu(\mathrm{CH})$ stretches can be observed in the region of $3000 \mathrm{~cm}^{-1}$ for both blends. A continuous decrease in absorption at these
Fig. 10 Temperature-programmed surface reaction (TPSR) from $T=383$ to $773 \mathrm{~K}$ and GHSV $=60,000 \mathrm{~h}^{-1}$, Gas composition: $8 \% \mathrm{H}_{2} \mathrm{O}, 8 \% \mathrm{O}_{2}$, $0 \% \mathrm{CO}_{2}$, ethanol: $160 \mathrm{ppm}$ (pure, green), 55 ppm (blend 1, blue), 25.9 ppm (blend 2, black), balance $\mathrm{N}_{2}$. All data filtered by a Savitzky-GolayFunction of 3rd polynomial order and a window size of 90 . Left axis: normalized hydrocarbon concentration, versus time since start of TPSR; right axis: mean catalyst temperature versus time

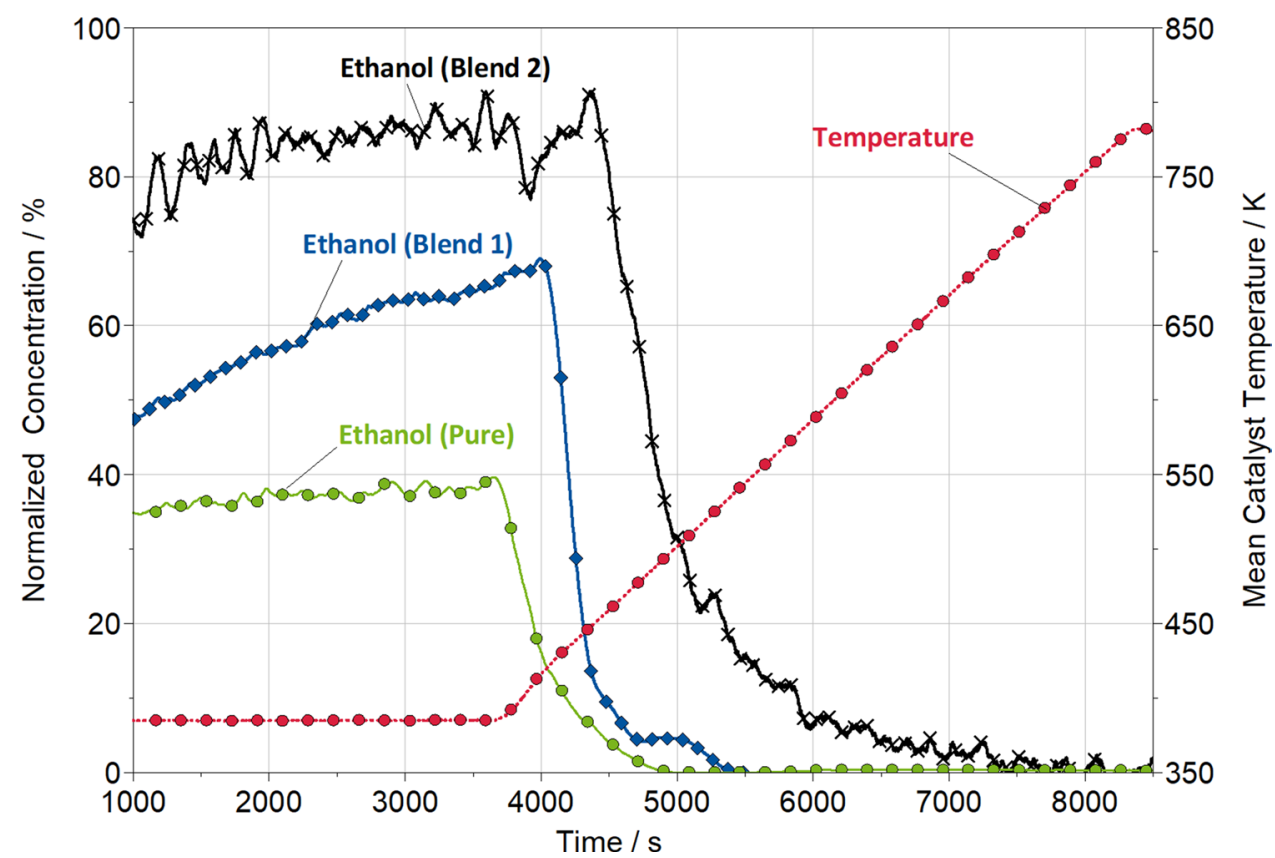


Fig. 11 Temperature-programmed surface reaction (TPSR) from $T=383$ to $773 \mathrm{~K}$ and GHSV $=60,000 \mathrm{~h}^{-1}$,

Gas composition: $8 \% \mathrm{H}_{2} \mathrm{O}$, $8 \% \mathrm{O}_{2}, 0 \% \mathrm{CO}_{2}$, cyclopentane: $72 \mathrm{ppm}$ (pure, orange), $16.5 \mathrm{ppm}$ (blend 1 , blue), 23.9 ppm (blend 2, black), balance $\mathrm{N}_{2}$. All data filtered by a Savitzky-Golay-Function of 3rd polynomial order and a window size of 90. Left axis: Normalized hydrocarbon concentration, versus time since start of TPSR; right axis: mean catalyst temperature versus time

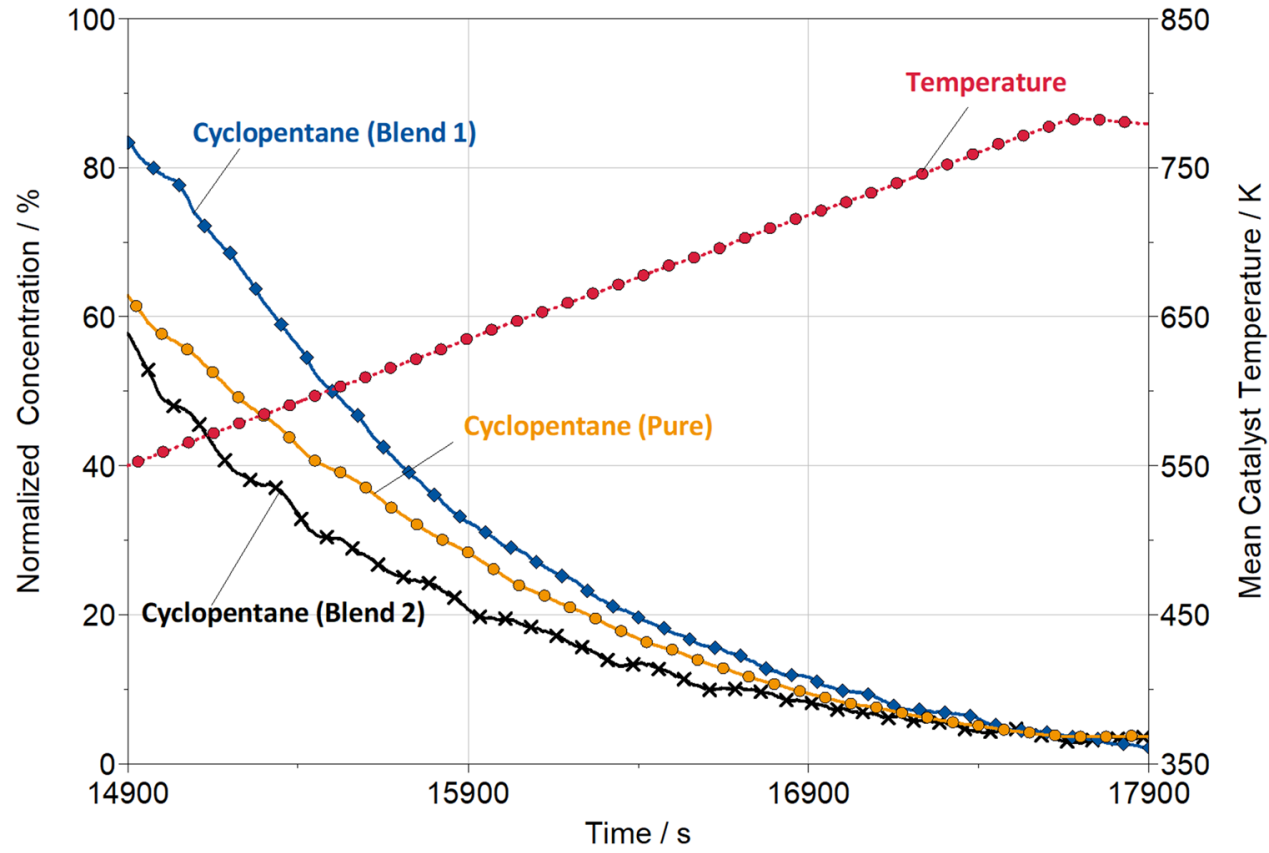

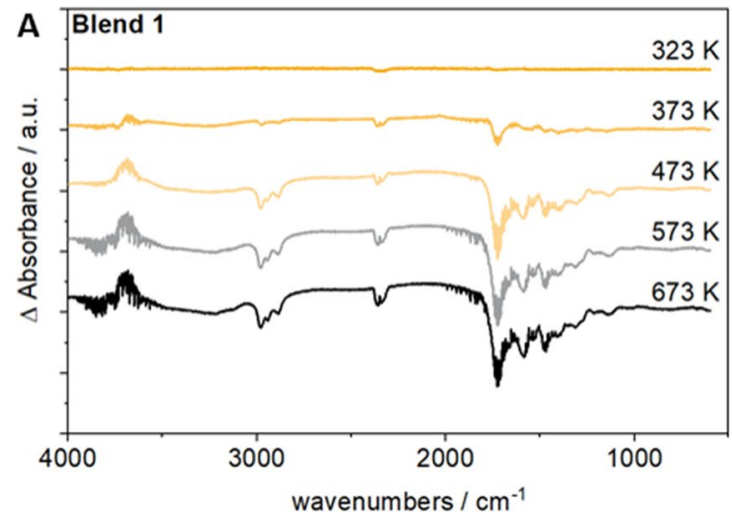

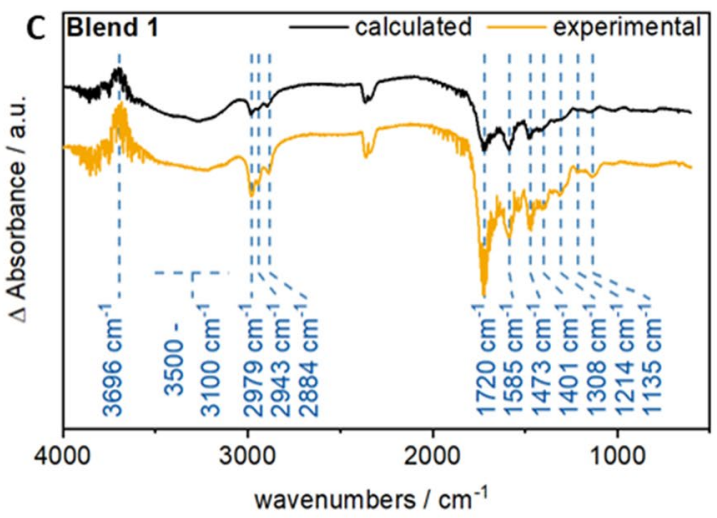

Fig. 12 A-B TP DRIFTS difference spectra of the blends at temperatures between 323 and $673 \mathrm{~K}$. C-D Comparison between TP DRIFTS difference spectra at $673 \mathrm{~K}$ for each blend as measured in the experiment and as calculated from the pure substance spectra. Increasing absorbance values are due to newly formed species, decreasing values
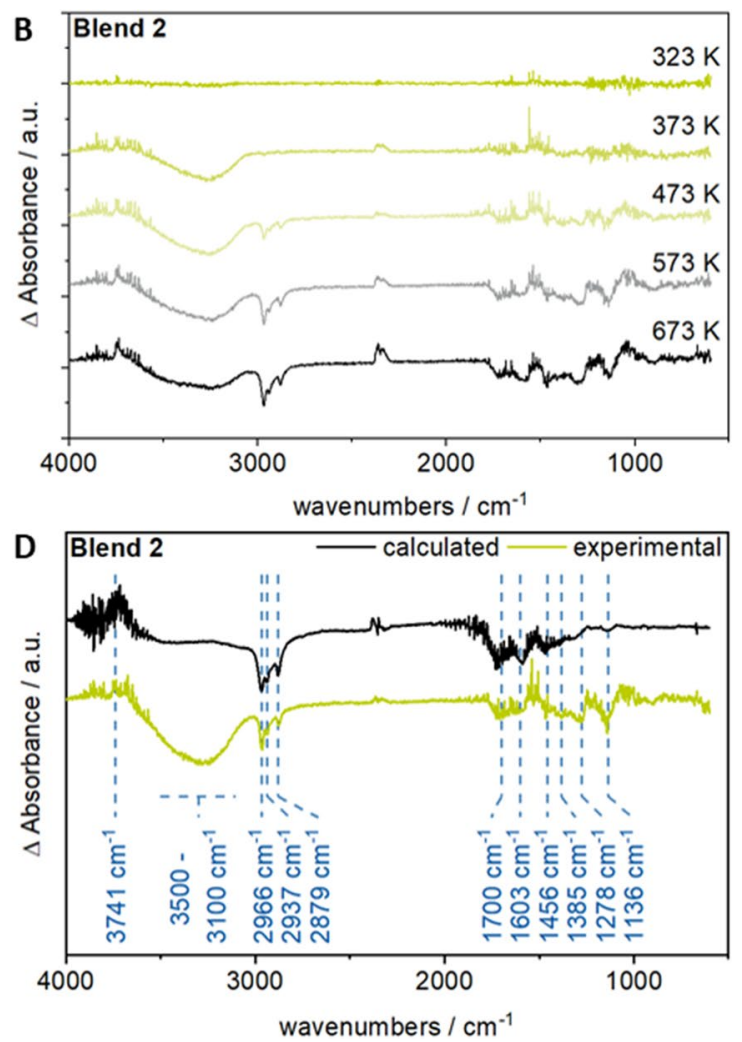

are caused by desorbing or decomposing species. Bands at 2360 and $2320 \mathrm{~cm}^{-1}$ stem from unavoidable, minor changes of $\mathrm{CO}_{2}$ presence in the IR spectrometer during the measurement which could not be excluded. The offset between individual spectra was added during data treatment for clarity 
wavenumbers indicates desorption of the HCs. The intensity of these bands is determined by the amount of adsorbed substance as well as the $\mathrm{CH}$-chain lengths.

The presence of water from either humidity or oxidation reactions is shown by its characteristic absorption spectrum in the region of $4000-3500 \mathrm{~cm}^{-1}$ and $2000-1250 \mathrm{~cm}^{-1}$ which sometimes overlay with the IR absorption bands of HC species.

The band at about $1700 \mathrm{~cm}^{-1}$, which is more pronounced in blend 1 due to the presence of ketones, is attributed to the characteristic $v(\mathrm{C}=\mathrm{O})$ vibration of either the $\mathrm{HC}$ itself (blend 1.2-butanone, cyclopentanone) or from partial oxidation products (e.g. aldehydes) of alcohols during the storage experiment $[42,48]$. Partial oxidation of alcohols also results in the observed absorption bands at about 1590 and $1475 \mathrm{~cm}^{-1}$ in blend 1 that have previously been attributed to the asymmetric and symmetric stretching of acetate species, respectively, in the case of ethanol [49, 50]. Although ethanol is also present in blend 2, we do not observe strong bands from these reaction intermediates indicating that the oxidation of ethanol is not occurring in significant amounts. Thus, TP-DRIFTS experiments support the observed, unexpected inhibition of the ethanol oxidation reaction in the presence of 1-butanol and cyclopentane.

Figure $12 \mathrm{c}$ and $\mathrm{d}$ show the comparison between the experimental difference spectra of blend 1 and 2 at $673 \mathrm{~K}$, respectively, in comparison to a theoretical difference spectra calculated from TP-DRIFTS spectra of the pure substances (see Supporting Information). In the case of blend 1 , we see particularly good agreement between theory and experiment. The broad band attributed to the intramolecular H-bonding between 3500 and $3100 \mathrm{~cm}^{-1}$ is more pronounced in the calculated case, which could be due to a more pronounced condensation in the case of the pure substance experiments. Interestingly, the case of blend 2 is reversed: the experiment-in contrast to the calculated spectrum-shows a very pronounced decrease in the broad band indicating the vanishing of formerly condensed species. Other absorption bands $[\nu(\mathrm{CH}), \nu(\mathrm{C}=\mathrm{O})]$ are relatively weakly pronounced. However, the region below $1400 \mathrm{~cm}^{-1}$ shows characteristic bands for cyclopentane (compared to pure substance spectrum). The bands observed in blend 2 (Fig. 12d) are more strongly pronounced compared to the experiment with pure cyclopentane, in which only very weak absorption bands were observed (Figure S1). These findings support the observations of the storage behavior at the LGB, in which cyclopentane alone showed very poor storage behavior, whereas the storage efficiency was drastically increased in blend 2 . A possible explanation is that the nonpolar rests of both alcohols could lead to an improved accumulation of cyclopentane.

\section{Conclusion}

In the presented study, a series production $\mathrm{Pt}-\mathrm{Pd} / \mathrm{Al}_{2} \mathrm{O}_{3}$ oxidation catalyst for lean-burn engines was investigated on a LGB with respect to its storage capacity and oxidative performance for five different HCs and two different blends. The storage investigations showed that generally in the presence of several HCs, these are stored in a smaller quantity than if they were dosed as pure components. The mixture of 1-butanol, ethanol and cyclopentane showed particular characteristics: the stored amount of 1-butanol was reduced in the presence of the other two substances, but the stored amount of ethanol and especially cyclopentane could be significantly increased by the presence of 1-butanol. The increase in ethanol storage can probably be explained by the formation of intramolecular $\mathrm{H}$ bonds between 1-butanol and ethanol. The high number of nonpolar groups of both alcohols could lead to an improved accumulation of cyclopentane. In addition, it could be shown that the stored amounts of 2-butanone and cyclopentanone in the blend are significantly reduced. This could indicate that both ketones compete for the same storage sites on the catalyst surface.

TPSR measurements were performed to investigate the oxidation behavior. The investigations showed that for both alcohols, 1-butanol and ethanol, a conversion of more than $50 \%$ occurred already at the start temperature of $383 \mathrm{~K}$. Both ketones, 2-butanone and cyclopentanone, showed a LO-temperature of $473 \mathrm{~K}$ and $505 \mathrm{~K}$ respectively. With a value of $576 \mathrm{~K}$, cyclopentane showed the highest LO-temperature. Cyclopentane was the only substance which could not be completely converted even at a temperature of $773 \mathrm{~K}$.

In general, it can be said that the presence of other blend components increased all LO-temperatures. Only in the case of cyclopentane could a reduction in LO temperature be demonstrated in the presence of 1-butanol and ethanol. Significant differences were found in the conversion of ethanol in the presence of 1-butanol and cyclopentane, with ethanol conversion at $383 \mathrm{~K}$ being only $17 \%$ compared to $>50 \%$ in the pure substance tests. Considering the previously mentioned assumption that this blend leads to many $\mathrm{H}$ bondings between ethanol and 1-butanol molecules, the deteriorated ethanol conversion could be associated with it.

The TP-DRIFTS analyses confirmed the LGB measurements. The formation of acetaldehyde and acetic acid by partial oxidation of ethanol was detected in the pure ethanol and blend 1 experiments. Also, the particularities of the investigations with blend 2 were confirmed with TP-DRIFTS.

Supplementary Information The online version contains supplementary material available at https://doi.org/10.1007/s10562-021-03771-w.

Acknowledgements The current work was funded by the Deutsche Forschungsgemeinschaft (DFG, German Research Foundation) under 
Germany's Excellence Strategy—Cluster of Excellence 2186, The Fuel Science Center"-ID: 390919832.

Funding Open Access funding enabled and organized by Projekt DEAL.

\section{Declarations}

Conflict of interest The authors declare that they have no conflicts of interest to this work.

Open Access This article is licensed under a Creative Commons Attribution 4.0 International License, which permits use, sharing, adaptation, distribution and reproduction in any medium or format, as long as you give appropriate credit to the original author(s) and the source, provide a link to the Creative Commons licence, and indicate if changes were made. The images or other third party material in this article are included in the article's Creative Commons licence, unless indicated otherwise in a credit line to the material. If material is not included in the article's Creative Commons licence and your intended use is not permitted by statutory regulation or exceeds the permitted use, you will need to obtain permission directly from the copyright holder. To view a copy of this licence, visit http://creativecommons.org/licenses/by/4.0/.

\section{References}

1. United Nations Framework Convention on Climate Change (UNFCCC) (2015) The Paris Agreement (FCCC/CP/2015/L.9/Rev.1). Available at: http://unfccc.int/resource/docs/2015/cop21/eng/ 109r01.pdf

2. Lei H, Rizzotto V, Guo A et al (2021) Recent understanding of low-temperature copper dynamics in $\mathrm{Cu}$-chabazite $\mathrm{NH}_{3}$-SCR catalysts. Catalysts 11:52. https://doi.org/10.3390/catal11010052

3. Jabłońska M, Palkovits R (2019) Perovskite-based catalysts for the control of nitrogen oxide emissions from diesel engines. Catal Sci Technol 9:2057-2077. https://doi.org/10.1039/c8cy0 $2458 \mathrm{~h}$

4. Schönebaum S, Dornseiffer P, Mauermann P et al (2021) Composition/performance evaluation of lean $\mathrm{NO}_{\mathrm{x}}$ trap catalysts for coupling with SCR technology. ChemCatChem. https://doi.org/ $10.1002 /$ cctc. 202001761

5. Hoppe F, Burke U, Thewes M et al (2016) Tailor-made fuels from Biomass: potentials of 2-butanone and 2-methylfuran in direct injection spark ignition engines. Fuel 167:106-117. https://doi. org/10.1016/j.fuel.2015.11.039

6. Wildenberg A, Fenard Y, Carbonnier M et al (2021) An experimental and kinetic modeling study on the oxidation of 1,3-dioxolane. Proc Combust Inst 38:543-553. https://doi.org/10.1016/j. proci.2020.06.362

7. Lehrheuer B, Hoppe F, Heufer KA et al (2019) Diethoxymethane as tailor-made fuel for gasoline controlled autoignition. Proc Combust Inst 37:4691-4698. https://doi.org/10.1016/j.proci.2018.07. 063

8. Burre J, Bongartz D, Deutz S et al (2021) Comparing pathways for electricity-based production of dimethoxymethane as a sustainable fuel. Energy Environ Sci 4:3754. https://doi.org/10.1039/ D1EE00689D

9. Hemken C, Burke U, Lam K-Y et al (2017) Toward a better understanding of 2-butanone oxidation: detailed species measurements and kinetic modeling. Combust Flame 184:195-207. https://doi. org/10.1016/j.combustflame.2017.06.007
10. Kerschgens B, Cai L, Pitsch H et al (2016) Di-n-buthylether, n-octanol, and n-octane as fuel candidates for diesel engine combustion. Combust Flame 163:66-78. https://doi.org/10.1016/j. combustflame.2015.09.001

11. Janssen AJ, Kremer FW, Baron JH et al (2011) Tailor-made fuels from biomass for homogeneous low-temperature diesel combustion. Energy Fuels 25:4734-4744. https://doi.org/10.1021/ef201 0139

12. Pischinger S, Hoppe F, Krieck M et al (2016) Fuel design for future combustion engines: a view from the cluster "Tailor-Made Fuels from Biomass". In: Lenz HP (ed) 37th International Vienna Motor Symposium 28-29 April, 2016: organized by the Austrian Society of Automotive Engineers (ÖVK) and the Institute for Powertrains and Automotive Technology, Vienna University of Technology; presented by Univ.-Prof. Dr. Hans Peter Lenz (VDI), vol 799. pp 224-252

13. Heywood JB (1988) Internal Combustion Engine Fundamentals. McGraw-Hill, New York

14. Dahmen M, Ottenwälder T, König A et al (2018) Co-optimization of fuel production and combustion: model-based fuel design, early-stage process evaluation, and engine testing \& optimization. In: 6th TMFB International Conference 2018 in Aachen, Germany

15. Bugosh GS, Harold MP (2017) Impact of zeolite beta on hydrocarbon trapping and light-off behavior on $\mathrm{Pt} / \mathrm{Pd} / \mathrm{BEA} / \mathrm{Al}_{2} \mathrm{O}_{3}$ monolith catalysts. Emiss Control Sci Technol 3:123-134. https://doi.org/ 10.1007/s40825-017-0061-7

16. Azambre B, Westermann A, Finqueneisel G et al (2015) Adsorption and desorption of a model hydrocarbon mixture over $\mathrm{HY}$ zeolite under dry and wet conditions. J Phys Chem C 119:315-331. https://doi.org/10.1021/jp509046n

17. Kanazawa T (2004) Development of hydrocarbon adsorbents, oxygen storage materials for three-way catalysts and NOx storagereduction catalyst. Catal Today 96:171-177. https://doi.org/10. 1016/j.cattod.2004.06.119

18. Russell A, Epling WS (2011) Diesel oxidation catalysts. Catal Rev 53:337-423. https://doi.org/10.1080/01614940.2011.596429

19. Нaaß F, Fuess H (2005) Structural characterization of automotive catalysts. Adv Eng Mater 7:899-913. https://doi.org/10.1002/ adem. 200500120

20. Katare S, Laing PM (2006) A hybrid framework for modeling aftertreatment systems: a diesel oxidation catalyst application. In: SAE 2006 World Congress, SAE Paper 2006-01-0689. SAE International, 400 Commonwealth Drive, Warrendale, PA

21. Heck RM, Farrauto RJ (2001) Automobile exhaust catalysts. Appl Catal A 221:443-457. https://doi.org/10.1016/S0926-860X(01) 00818-3

22. Sampara CS, Bissett EJ, Assanis D (2008) Hydrocarbon storage modeling for diesel oxidation catalysts. Chem Eng Sci 63:51795192. https://doi.org/10.1016/j.ces.2008.06.021

23. Girard J, Snow R, Cavataio G et al (2008) Influence of hydrocarbon storage on the durability of SCR catalysts. In: SAE 2008 World Congress, SAE Paper 2008-01-0767. SAE International, 400 Commonwealth Drive, Warrendale, PA

24. Wolkenar B, Schönebaum S, Mauermann P et al (2019) Storage and oxidation of oxygen-free and oxygenated hydrocarbons on a Pt-Pd Series production oxidation catalyst. Top Catal 62:376385. https://doi.org/10.1007/s11244-018-1109-9

25. Manula T, Suopanki A, Torkell K et al (2004) The optimization of light-duty diesel oxidation catalysts for preturbo, closed-coupled and underfloor positions. In: SAE transactions, Vol. 113, section 4: Journal of Fuels And Lubricants, SAE Paper 2004-013021. SAE International, 400 Commonwealth Drive, Warrendale, PA

26. Liu B, Yao D, Wu F et al (2019) Experimental investigation on $\mathrm{N}_{2} \mathrm{O}$ formation during the selective catalytic reduction of $\mathrm{NOx}$ 
with $\mathrm{NH}_{3}$ over $\mathrm{Cu}$-SSZ-13. Ind Eng Chem Res 58:20516-20527. https://doi.org/10.1021/acs.iecr.9b03294

27. RÖMPP-Redaktion, Weber-Mußmann A, Butanole, RD-02-03077 (2015) in Böckler F, Dill B, Dingerdissen U, Eisenbrand G, Faupel F, Fugmann B, Gamse T, Matissek R, Pohnert G, Sprenger G, RÖMPP [Online], Stuttgart, Georg Thieme Verlag, [August 2021]. https://roempp.thieme.de/lexicon/RD-02-03077

28. RÖMPP-Redaktion, Ortelt M, Butan-2-on, RD-02-03080 (2019) in Böckler F, Dill B, Dingerdissen U, Eisenbrand G, Faupel F, Fugmann B, Gamse T, Matissek R, Pohnert G, Sprenger G, RÖMPP [Online], Stuttgart, Georg Thieme Verlag, [August 2021]. https://roempp.thieme.de/lexicon/RD-02-03080

29. RÖMPP-Redaktion, Cyclopentan, RD-03-03172 (2018) in Böckler F, Dill B, Dingerdissen U, Eisenbrand G, Faupel F, Fugmann B, Gamse T, Matissek R, Pohnert G, Sprenger G, RÖMPP [Online], Stuttgart, Georg Thieme Verlag, [August 2021]. https://roempp. thieme.de/lexicon/RD-03-03172

30. RÖMPP-Redaktion, Cyclopentanon, RD-03-03175 (2018) in Böckler F, Dill B, Dingerdissen U, Eisenbrand G, Faupel F, Fugmann B, Gamse T, Matissek R, Pohnert G, Sprenger G, RÖMPP [Online], Stuttgart, Georg Thieme Verlag, [August 2021]. https:// roempp.thieme.de/lexicon/RD-03-03175

31. RÖMPP-Redaktion, Baum M, Ethanol, RD-05-01878 (2019) in Böckler F, Dill B, Dingerdissen U, Eisenbrand G, Faupel F, Fugmann B, Gamse T, Matissek R, Pohnert G, Sprenger G, RÖMPP [Online], Stuttgart, Georg Thieme Verlag, [August 2021]. https:// roempp.thieme.de/lexicon/RD-05-01878

32. Méndez-Román R, Cardona-Martínez N (1998) Relationship between the formation of surface species and catalyst deactivation during the gas-phase photocatalytic oxidation of toluene. Catal Today 40:353-365. https://doi.org/10.1016/S0920-5861(98) 00064-9

33. Oh H, Luo J, Epling WS (2011) NO oxidation inhibition by hydrocarbons over a diesel oxidation catalyst: reaction between surface nitrates and hydrocarbons. Catal Lett 141:1746-1751. https://doi. org/10.1007/s10562-011-0714-z

34. Peral J, Ollis D (1992) Heterogeneous photocatalytic oxidation of gas-phase organics for air purification: acetone, 1-butanol, butyraldehyde, formaldehyde, and m-xylene oxidation. J Catal 136:554-565. https://doi.org/10.1016/0021-9517(92)90085-V

35. Hazlett MJ, Moses-Debusk M, Parks JE et al (2017) Kinetic and mechanistic study of bimetallic Pt-Pd/ $\mathrm{Al}_{2} \mathrm{O}_{3}$ catalysts for $\mathrm{CO}$ and $\mathrm{C}_{3} \mathrm{H}_{6}$ oxidation. Appl Catal B 202:404-417. https://doi.org/10. 1016/j.apcatb.2016.09.034

36. Gonugunta P, Dugulan AI, Bezemer GL et al (2021) Role of surface carboxylate deposition on the deactivation of cobalt on titania Fischer-Tropsch catalysts. Catal Today 369:144-149. https://doi. org/10.1016/j.cattod.2020.04.037

37. Mavrikakis M, Barteau MA (1998) Oxygenate reaction pathways on transition metal surfaces. J Mol Catal A 131:135-147. https:// doi.org/10.1016/S1381-1169(97)00261-6
38. Avgouropoulos G, Oikonomopoulos E, Kanistras D et al (2006) Complete oxidation of ethanol over alkali-promoted $\mathrm{Pt} / \mathrm{Al}_{2} \mathrm{O}_{3}$ catalysts. Appl Catal B 65:62-69. https://doi.org/10.1016/j.apcatb. 2005.12.016

39. Li X, Iglesia E (2007) Selective catalytic oxidation of ethanol to acetic acid on dispersed Mo-V-Nb mixed oxides. Chemistry 13:9324-9330. https://doi.org/10.1002/chem.200700579

40. Letichevsky S, Zonetti PC, Reis PPP et al (2015) The role of $\mathrm{m}-\mathrm{ZrO}_{2}$ in the selective oxidation of ethanol to acetic acid employing $\mathrm{PdO} / \mathrm{m}-\mathrm{ZrO}_{2}$. J Mol Catal A 410:177-183. https://doi.org/10. 1016/j.molcata.2015.09.012

41. Liu J, Li J, Hou X et al (2020) Thermal stabilities of MCM41-modified $\mathrm{Pd} / \mathrm{Al}_{2} \mathrm{O}_{3}$ for ethanol adsorption and oxidation. Ind Eng Chem Res. https://doi.org/10.1021/acs.iecr.9b06258

42. Raskó J, Kiss J (2005) Adsorption and surface reactions of acetaldehyde on $\mathrm{TiO}_{2}, \mathrm{CeO}_{2}$ and $\mathrm{Al}_{2} \mathrm{O}_{3}$. Appl Catal A 287:252-260. https://doi.org/10.1016/j.apcata.2005.04.003

43. de Lima AFF, Colman RC, Zotin FMZ et al (2010) Acetaldehyde behavior over platinum based catalyst in hydrogen stream generated by ethanol reforming. Int J Hydrog Energy 35:13200-13205. https://doi.org/10.1016/j.ijhydene.2010.09.030

44. Yamashita T, Ninagawa S, Kato T (1976) Synthesis of acetic acid by catalytic oxidation of butenes (part 1). Bull Jpn Pet Inst 18:167-177. https://doi.org/10.1627/jpi1959.18.167

45. Yamashita T, Matsuzawa Y, Ninagawa S (1977) Synthesis of acetic acid by catalytic oxidation of butenes (part 2). Bull Jpn Pet Inst 19:109-118. https://doi.org/10.1627/jpi1959.19.109

46. Jahan I, Kung HH (1992) Effect of water on the oxidation of 2-butanone on vanadium oxide. Ind Eng Chem Res 31:23282331. https://doi.org/10.1021/ie00010a011

47. Liu X (2008) DRIFTS study of surface of $\gamma$-alumina and its dehydroxylation. J Phys Chem C 112:5066-5073. https://doi.org/10. 1021/jp711901s

48. Schmal M, Cesar DV, Souza MMVM et al (2011) Drifts and TPD analyses of ethanol on Pt catalysts over $\mathrm{Al}_{2} \mathrm{O}_{3}$ and $\mathrm{ZrO}_{2}$ - partial oxidation of ethanol. Can J Chem Eng 89:1166-1175. https://doi. org/10.1002/cjce.20597

49. de Mello LF, Noronha FB, Schmal M (2003) NO reduction with ethanol on $\mathrm{Pd}-\mathrm{Mo} / \mathrm{Al}_{2} \mathrm{O}_{3}$ catalysts. J Catal 220:358-371. https:// doi.org/10.1016/S0021-9517(03)00272-0

50. Greenler RG (1962) Infrared study of the adsorption of methanol and ethanol on aluminum oxide. J Chem Phys 37:2094-2100. https://doi.org/10.1063/1.1733430

Publisher's Note Springer Nature remains neutral with regard to jurisdictional claims in published maps and institutional affiliations. 